\title{
Effect of host-rock rheology on dyke shape, thickness and magma overpressure
}

\author{
Rémi Vachon and Christoph F. Hieronymus \\ Department of Earth Sciences, Uppsala Universitet, Villavägen 16, SE-75236 Uppsala, Sweden. E-mail: remi.vachon@geo.uu.se
}

Accepted 2016 November 30. Received 2016 September 12; in original form 2016 March 2

\begin{abstract}
S UMMAR Y
The size and thickness of dykes is of fundamental importance for volcano dynamics because dykes are the primary path for magma transport, and because large numbers of dykes often comprise a major proportion of the volcanic edifice and of the underlying crust. Standard elastic models predict dyke geometry to be elliptic in cross-section for constant overpressure and uniform host-rock properties, whereas observations show that dyke thickness is typically more nearly constant with a sharp taper at the ends. Moreover, the predicted overpressures required to inflate dykes in a purely elastic medium are often significantly higher ( $>150 \mathrm{MPa}$ and up to $2 \mathrm{GPa}$ ) than those estimated by other means (about 1-50 MPa). In this study, we use 2-D finite element models to test whether other host-rock rheologies lead to more realistic dyke shapes and overpressures. We examine three different rheologies, each of which is affected by the presence of the dyke itself: (1) elasticity with reduced moduli in regions of low pressure or tension; (2) elastoplasticity with plastic failure in the high-stress regions surrounding the dyke tips; (3) viscoelasticity with a viscosity decrease due to heating by the dyke. We use rheological parameters obtained from laboratory experiments whenever possible, and assume static conditions for the final dyke shape. We find that all three rheologies tend to make the dyke more rectangular relative to the elliptical dykes of the linearly elastic models. The change in shape is due to enhanced deformation in the high-stress zone surrounding the dyke tip. We also find that the overpressure required to inflate an initially thin dyke to a given thickness is reduced for all three rheologies. The greatest decrease in overpressure by a factor of about 0.1 is observed for the elastoplastic model, and for the viscoelastic model if the dyke intrudes into moderately pre-heated host-rock. We discuss our results with respect to dyke observations from Rum Island (Scotland) and use these as a guide to evaluate our models.
\end{abstract}

Key words: Numerical solutions; Plasticity, diffusion, and creep; Elasticity and anelasticity; Mechanics, theory, and modelling; Rheology: crust and lithosphere; Physics of magma and magma bodies.

\section{INTRODUCTION}

Dykes constitute the main mode of magma transport and storage in the Earth's brittle crust. Dyke thickness is a critical parameter that controls the volumetric flow rate or effusion rate in an eruption and determines the efficiency and distance over which magma transport is possible (Rubin 1993). It also strongly affects the degree to which magma is contaminated by the host rock (Bruce \& Huppert 1990; Reiners et al. 1995; Krumbholz et al. 2014), and it controls the geometry and dynamics of magmatic intrusions in and underneath volcanoes and at accretionary plate boundaries (Annen et al. 2001; Qin \& Buck 2008). Under the simplest assumptions of a static dyke emplaced in a linear elastic medium, dyke thickness is an analytical function of dyke length and magma overpressure and the dyke is elliptical in cross-section (Sneddon \& Lowengrub 1969).
This analytical solution is commonly used to compute magma overpressures in non-feeder dyke systems (Kavanagh \& Sparks 2011; Daniels et al. 2012; Becerril et al. 2013; Kusumoto et al. 2013) based on observations of dyke geometry and knowledge of the host rock's elastic moduli. Typically derived values for magma overpressure are in the range of a few $\mathrm{MPa}$ to a few tens of $\mathrm{MPa}$ (Pollard \& Muller 1976; Poland et al. 2008; Geshi et al. 2010; Daniels et al. 2012; Kusumoto et al. 2013). These calculated overpressures compare well with independent estimates based on the tendency for dyke propagation rather than dyke inflation (Spence \& Turcotte 1985; Karlstrom et al. 2009), thermal considerations for long-distance dyke propagation (Jellinek \& DePaolo 2003), and surface deformations (Newman et al. 2001). However, some calculated magma overpressures are significantly higher than the above values. Poland et al. (2008) report overpressures of up to $150 \mathrm{MPa}$, 
while Daniels et al. (2012) calculate overpressures that approach $2 \mathrm{GPa}$. In the latter case, the overpressure estimate may be reduced if the observed dykes are interpreted as segments of a larger dyke rather than individual dykes. But even for very closely spaced segments, the pressure estimate will not be reduced by a factor greater than five (Daniels et al. 2012), thus yielding a minimum estimate of $400 \mathrm{MPa}$. It is presently not clear whether some dykes have significantly higher overpressure than others, whether the elastic moduli used in the calculations are too high, or whether the linear elastic model is inadequate to describe host rock deformation.

Where dykes are well exposed, it is sometimes possible to recover a detailed thickness profile along the entire length of the dyke (Pollard \& Muller 1976; Kavanagh \& Sparks 2011; Daniels et al. 2012). The first-order observation is that dyke shapes are generally complex with significant variability at length scales that are much shorter than the length of the dyke. This complexity probably owes to small-scale heterogeneity in rock properties, in particular the difference between pristine and pre-fractured rock (Kusumoto $\&$ Gudmundsson 2014). On the scale of the dyke length, the smallscale complexity may be neglected, and observations indicate that thickness is often much more constant over the central portion of the dyke than predicted by linear elasticity theory, while the taper is more localized towards the ends (Rasmussen 1978; Gudmundsson 1995; Hoek 1995; Maaløe 1998; Kavanagh \& Sparks 2011). The poor fit of the linear elastic solution to natural dyke shapes is a strong indicator that the assumption of linear elastic behaviour of the host rock is an oversimplification.

If dyke length and maximum thickness can be observed directly or inferred from near-dyke tip measurements, it is possible to calculate a minimum value of the fracture toughness of the host rock (Delaney \& Pollard 1981; Rubin \& Pollard 1987). The fracture toughnesses thus calculated fall within a narrow range of about $30-150 \mathrm{MPa}$ $\mathrm{m}^{1 / 2}$ for a variety of rock types (Delaney \& Pollard 1981; Rubin \& Pollard 1987; Parfitt 1991; Rivalta \& Dahm 2006; Gudmundsson 2009). This good agreement of the calculated fracture toughnesses is often interpreted as a validation of the underlying elastic model. On the other hand, laboratory measurements of fracture toughness are significantly lower, ranging from less than $1 \mathrm{MPam}^{1 / 2}$ toabout $2 \mathrm{MPam}^{1 / 2}$ (Clifton et al. 1976; Atkinson 1984). Since the laboratory measurements involve the known fluid pressure, while measurements based on dykes use the pressure computed from dyke length and thickness, it is possible that the discrepancy originates from large-scale inelastic rock deformation outside of the small process zone surrounding the dyke-tip (Rubin \& Pollard 1987). It is these large-scale deformations due to viscous, plastic, and nonlinear elastic host-rock behaviour that are the subject of this study.

It is generally established that rocks display linear elastic behaviour over short timescales when subjected to low stresses and strains. When these conditions are not met, however, rock rheology is more complicated. Over relatively long timescales, moderately hot rock flows by viscous creep mechanisms (Ranalli 1995). At high stress and strain, rock fails either plastically or by fracturing and subsequent frictional slip on the newly created fracture surfaces (Ranalli 1995). Moreover, most rock types are porous with voids that close at low to moderate pressures, thus leading to pressuredependent elastic moduli (Walsh 1965; Henyey \& Pomphrey 1982). Since the effects of inelastic or nonlinear elastic rheologies are observed in nature and are reasonably well quantified by laboratory experiments, it is prudent to test their effects on dyke models. If the results differ significantly from those of the linear elastic models, then the results of the simple elastic models and their predictions must be challenged.
Unfortunately, there is at present no direct experimental evidence that can shed light on the nature of the large-scale deformations surrounding dykes or similar fluid-filled fractures. In particular, the direct link between fluid pressure and fracture aperture is missing. Exposed dykes can provide a complete thickness profile and allow access to the deformed host rock, but direct measurements of magma overpressure are not available. Hydraulic fracturing, a common technique in the hydrocarbon industry, is dynamically similar to the process of dyking. Fluid pressure is carefully controlled and monitored, but the thickness profile of the fracture is largely inaccessible because of the thickness of the overlying rock (although there have been recent advances in in-situ monitoring of fracture thickness and shape in laboratory-scale fracture propagation experiments using seismic methods (Groenenboom \& van Dam 2000)). Experiments using analogue materials such as gelatine (Kavanagh et al. 2013) can provide the link between fluid overpressure and fracture aperture, but the material does not scale appropriately because gelatine remains mostly elastic even at very high strains so that the non-elastic effects in question are not present.

In this contribution, we build on the static elastic models but allow for more realistic host rock rheologies. Three different rheologies are tested: (1) Elasticity with reduction of the elastic moduli in regions of low pressure. From near-surface conditions down to depths of a few kilometres, pressure has a significant effect on the elastic moduli due to opening or closing of voids in the form of pores or cracks (Walsh 1965; Henyey \& Pomphrey 1982). Surrounding the dyke tip, pressure is strongly reduced due to deformations induced by the dyke itself so that the effective host-rock compliance changes by as much as an order of magnitude as a function of position. (2) Elastoplasticity. Shear fracture occurs when a combination of shear stresses and pressure reaches the failure strength envelope (Paterson \& Wong 2005). Once a fracture network has been established, additional strain can be accommodated by frictional sliding at constant driving stress. This behaviour is adequately described by elastoplasticity (Saxena \& Landes 1989; Lawn 1993). Atomic-scale mechanisms such as the Peierls mechanism may also contribute to plastic behaviour, but these typically require high confining pressures and high driving differential stresses (Paterson \& Wong 2005). (3) Viscoelasticity with temperature-dependent viscosity. At elevated temperatures, all rocks deform increasingly by ductile creep which may be modelled as viscous flow. As heat diffuses out of the dyke, the viscosity is reduced in the vicinity of the dyke and significant permanent deformation may ensue.

The purpose of this study is to map out the effects of host-rock rheology on shape and thickness of the dyke. While we do compute best fits of each of the models to three different dyke thickness profiles, we make no attempt at an overall best fit that incorporates multiple processes. In particular, we neglect the possible effects of buoyancy or variable regional stress as these would introduce too many independent degrees of freedom and would probably not provide much insight into the overall viability of the different rheological models.

\section{METHODS}

The aim of our study is to compute dyke thickness profiles of static dykes, that is, when all transient effects due to fluid flow and fracture propagation have subsided. We follow the concept of the analytical solution by Sneddon \& Lowengrub (1969) and calculate dyke thickness by inflating an initially thin crack with constant overpressure. By doing so, we tacitly assume that the final result is 
(a)

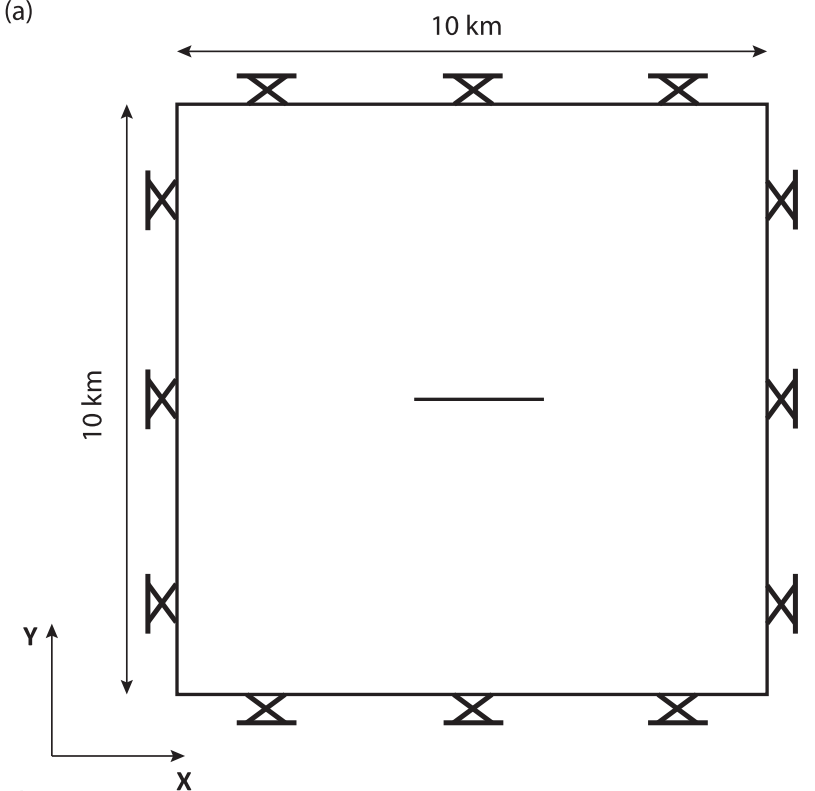

(b)

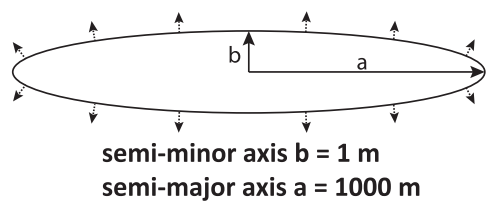

Figure 1. Model setup. (a) Model configuration and boundary conditions for all models. A narrow initial crack is placed inside a 2-D box of host-rock with parameters appropriate for sandstone. Two sets of models treat the third dimension either as plane strain or as axisymmetric. The far-field boundaries are fixed and have only a negligible influence on the solution. (b) The initial crack is elliptical with semi-major axis $a=1000 \mathrm{~m}$ and semi-minor axis $b=1 \mathrm{~m}$. A constant overpressure is applied on the inside boundaries of the crack (indicated by arrows).

independent of the dynamical path taken in forming the dyke. This is certainly the case for the (reversible) elastic models, and also for the viscoelastic case provided that dyke propagation is fast relative to the heat diffusion timescale. For the plastic case, solutions may differ depending on whether the dyke was formed by hydraulic fracturing or by intrusion into a pre-existing fracture. We focus on the simplest case of dyke inflation as this provides a uniquely defined solution. The modelling approach is largely identical for the three rheologies under consideration. However, while the elastic and elastoplastic models are purely static with the magma merely providing a pressure boundary condition, the viscoelastic model must include the spatiotemporal cooling of the magma as well. These differences are described in the section on rheology below.

\subsection{Model setup}

We construct our model in a 2-D geometry, but we allow for different behaviour in the third dimension by making different assumptions about symmetry. In one set of models, we use a Cartesian setup with plane-strain conditions. In these models, the dyke is implicitly assumed to be infinitely long in the dimension not modelled. In the second set of models, we employ an axisymmetric symmetry which is appropriate for a dyke that is perfectly circular in its two longer dimensions. We did not test fully 3-D models because there are no 3-D dyke thickness observations for comparison that would warrant such complexity.

Our Cartesian and axisymmetric models are identical in crosssection with $x$ - and $y$-coordinates (Fig. 1a). In the axisymmetric models, the $x$-coordinate corresponds to the radial direction. The model domain is $10 \mathrm{~km} \times 10 \mathrm{~km}$ in size with no-slip boundary conditions. At the centre of the model, we introduce a narrow crack in the form of an ellipsoidal void (Figs 1a and b) with semi-major axis length of $2 \mathrm{~km}$ and semi-minor axis of length $1.0 \mathrm{~m}$, which gives an initial aspect ratio of $10^{-3}$. For the elastic and elastoplastic models, it is only the relative sizes which are important. For the viscoelastic models, on the other hand, the absolute size of the problem is a critical parameter, and for consistency we use the same setup for all rheological models. We tested different initial crack thicknesses and shapes (e.g. rectangular with semi-circular ends), and verified that our assumptions about the initial crack have only negligible effects on the final model results. Similarly, we verified that the size of the model domain relative to the dyke size is large enough so that stresses nearly vanish at the outer boundaries and the model results are not significantly affected by the domain size.

For the viscoelastic models, the overburden has no effect and the results are completely specified by the magma overpressure relative to the overburden pressure. For the elastic models with pressuredependent moduli, and for the elastoplastic models, the overburden pressure affects the rheology, and we ran the models with different initial background pressures as indicated.

The dynamical system is solved using the commercial finite element code 'Comsol Multiphysics 4.4'. The model domain is discretized using a Lagrangian mesh with about 45000 quadrilateral elements of quadratic integration order. The resolution varies from around $1 \mathrm{~m}$ in the vicinity of the dyke tips to around $150 \mathrm{~m}$ at the model edges. The dyke is inflated by applying a constant normal stress to the fracture surface. Inertial as well as gravitational effects are neglected so that the momentum equation becomes

$\nabla \cdot \sigma=0$

where $\sigma$ is the stress tensor, and $\nabla$ is the 2-D nabla-operator in the plane of interest and in the appropriate coordinate system (Timoshenko \& Goodier 1970).

\subsection{Rheology}

All models are based on linear elasticity theory with

$\sigma_{i j}=K \varepsilon_{k k} \delta_{i j}+2 G\left(\varepsilon_{i j}-\frac{1}{3} \varepsilon_{k k} \delta_{i j}\right)$

where $\boldsymbol{\varepsilon}$ is the strain tensor, and $K$ and $G$ are the bulk and shear modulus, respectively. Finite-strain theory is used for the purely elastic model which locally exhibits large elastic strains of several per cent, while small-strain elasticity is sufficient for the other models.

\subsection{Elasticity with pressure-dependent moduli}

The first set of models is purely elastic, but the elastic moduli are both functions of pressure, that is,

$K=K(p), \quad G=G(p)$

Pressure-dependent compliance of rock is commonly observed under near-surface conditions for pressures ranging from $0 \mathrm{~Pa}$ up to about $100 \mathrm{MPa}$. The effect is generally ascribed to cracks and pores of different shape and size closing gradually as the pressure is increased (Walsh 1965; Henyey \& Pomphrey 1982). The elastic stiffness of the material increases as the void ratio decreases up to a limiting pressure at which essentially all voids are closed. The dynamical system is nonlinear because the displacements caused by the dyke affect the pressure solution, which results in a feedback due to changing elastic stiffness. 

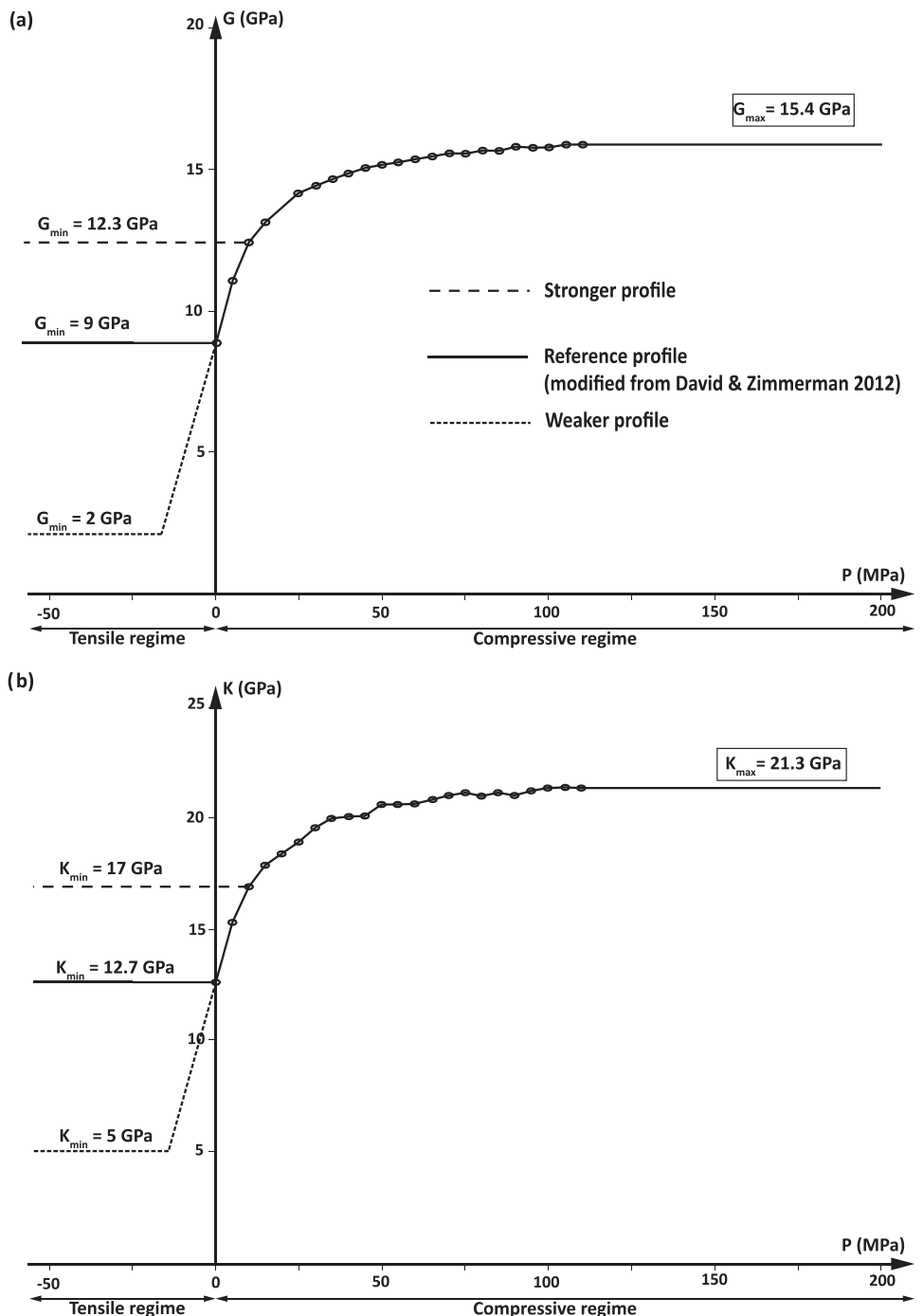

Figure 2. Pressure-dependent moduli for the nonlinear elastic model based on measurements of a Torridonian sandstone (David \& Zimmerman 2012). Three different extrapolations are used in the tensile regime where data are unavailable (see the text for details). (a) Shear modulus, and (b) bulk modulus as function of pressure.

Elastic moduli can either be measured directly using slow or quasi-static deformation (static moduli), or they can be computed from the natural frequencies in vibrational experiments (dynamic moduli). For our analysis, it is the static moduli that are relevant. However, vibrational experiments are generally easier to perform, and thus most experimental data is in the form of dynamic moduli. The dynamic moduli are typically lower than the static ones by a factor of 2 to 3 in the low-pressure regime and converge at higher pressures (Asef \& Najibi 2013). For our numerical experiments, we use dynamic moduli as these are the only type of data available for sandstone, which is the rock type hosting the dykes for which we have thickness data. Our elastic moduli are based on the Vosges sandstone model of David \& Zimmerman (2012), which has asymptotic moduli similar to the dyke-hosting Torridonian sandstone (Khazanehdari \& Sothcott 2003). Since the asymptotic high-pressure moduli of the two types of sandstone do not match precisely, we shift the $K(p)$ and $G(p)$ profiles for the Vosges sandstone vertically in order to impose such a fit (see Figs 2a and b). There generally is a region of net tensile stress surrounding the dyke tips, but rheological measurements typically do not provide data for this regime due to experimental difficulties. It is therefore necessary to extrapolate the $K(p)$ and $G(p)$-curves to low compressive and tensile pressures. In order provide a range of estimates, we test three different extrapolations (Figs 2a and b): (1) a set of reference curves derived from the data as described above and with constant moduli in the tensile regime which are equal to the minimum values at zero pressure; (2) a set of curves for a weaker material with linear extrapolation into the tensile regime down to values of $K=5 \mathrm{GPa}$ and $G=2 \mathrm{GPa}$ below which the moduli are assumed to be constant; and (3) a set of curves for a stronger material with constant minimum values set at $K=17 \mathrm{GPa}$ and $G=12.3 \mathrm{GPa}$. The resulting variability in model compliances by a factor of about 4 is probably sufficient to cover also the uncertainties due to rock types and static versus dynamic moduli described above.

\subsection{Plasticity}

Observations show that rocks cannot support large elastic shear strains. In the brittle regime, rocks fail at elastic strains of the order 


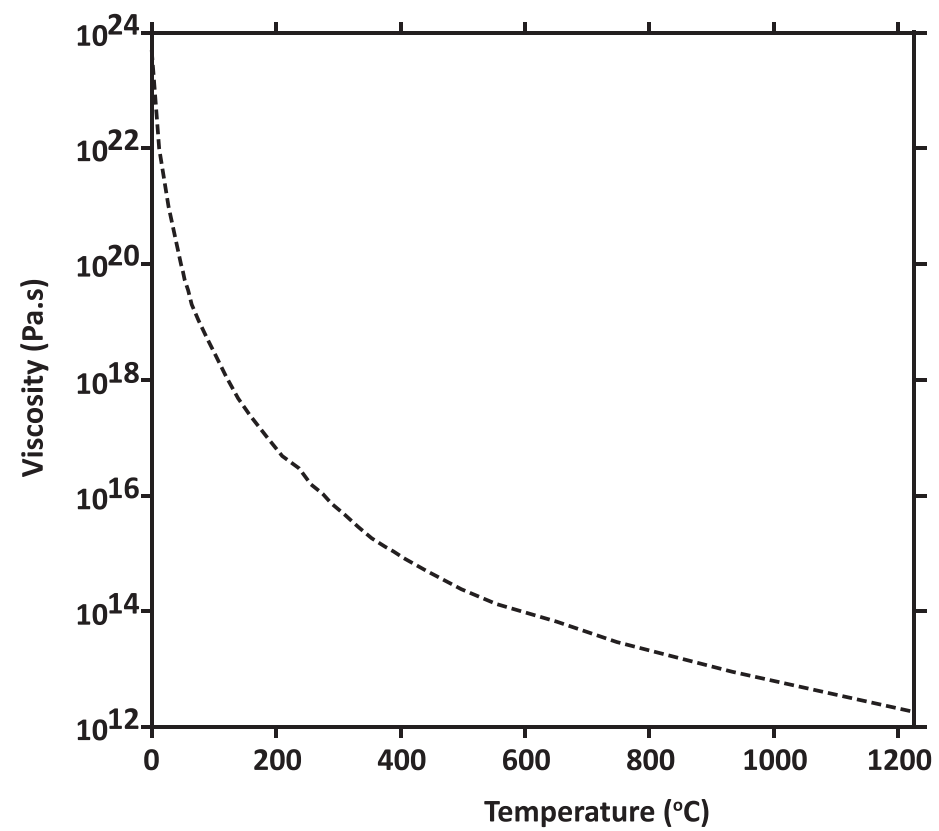

Figure 3. Temperature dependence of viscosity for dry quartzite host-rock used in the viscoelastic models (Ranalli 1995).

of about 0.1 per cent, beyond which permanent deformation occurs. On the microscopic scale (e.g. at the tips of small cracks), such permanent deformation is due to dislocations in the crystal lattice of individual minerals (Lawn 1993) or due to microcracking at the intermediate scale of mineral grains (Paterson \& Wong 2005). For the dyke problem, the relevant spatial scale is probably much larger, and the permanent deformations are probably due to brecciation and frictional sliding (Rudnicki \& Rice 1975; Rubin 1993). Various yield criteria and flow rules have been suggested for brittle materials (Vermeer \& De Borst 1984; Paterson \& Wong 2005). We use the Drucker-Prager yield criterion which accurately takes pressure dependence into account. The criterion is similar to the Coulomb criterion, but has a simpler and numerically more robust treatment of the intermediate stress. The appropriate criterion for most rocks is somewhere between the Coulomb and the Drucker-Prager criterion (Paterson \& Wong 2005).

In small-strain theory, plastic and elastic strains are additive,

$\varepsilon_{t}=\varepsilon_{p}+\varepsilon_{e}$

where $\varepsilon_{t}$ is the total strain, $\varepsilon_{p}$ is the plastic strain, and $\varepsilon_{e}$ is the elastic strain used in (2). The yield criterion is defined by

$f\left(\sigma_{i j}\right)=\sqrt{J_{2}}-k+\alpha p=0$

where $J_{2}$ is the second invariant of the stress deviator and $\alpha$ gives the pressure-dependence of the yield stress (Paterson \& Wong 2005). Parameter $k$ is a scaled form of the cohesion which is related to the cohesion $C$ of the Coulomb formulation and the yield strength $\sigma_{y}$ of the von-Mises formulation by $C=\sigma_{y}=\sqrt{3} k$. Both $k$ and $\alpha$ are taken as constants so that there is no strain hardening (or strain softening) of the material. Plastic flow is derived from the potential

$g\left(\sigma_{i j}\right)=\sqrt{J_{2}}-k+\beta p$

where $\beta$ is the dilatancy factor. For small strains, rocks typically exhibit volume expansion which corresponds to $\beta>0$ (Paterson $\&$ Wong 2005). However, this dilatancy decreases with increasing strain, and for simplicity we set $\beta=0$ in our models. The flow rule is thus non-associative as $\beta \neq \alpha$. Fluids and volatiles at elevated pressure in the host-rock may have a significant effect on rock strength and friction which is difficult to quantify, and thus in our experiments we test different values of both $k$ and $\alpha$.

\subsection{Viscoelasticity}

At high temperature, rocks are observed to flow as the result of various creep mechanisms (Ranalli 1995). Most of these mechanisms result in a power-law rheology. However, large strains of order unity are required in order to reach the equilibrium power law (Paterson \& Wong 2005). We avoid the complications due to transient and nonlinear rheologies and assume a Newtonian viscosity with temperature dependence. For a Maxwell viscoelastic material, the total strain is the sum of the elastic and viscous strains (Turcotte \& Schubert 2002),

$\varepsilon_{t}=\varepsilon_{e}+\varepsilon_{v}$

The viscous flow is assumed to be incompressible with viscous strain rates given by

$\sigma_{i j}^{\prime}=2 \eta(T) \dot{\varepsilon}_{i j}$

where $\sigma^{\prime}$ indicates the deviatoric stress tensor. The temperature dependence of the viscosity, $\eta(T)$ (see Fig. 3), is entered into the model in tabular form from empirical data for dry quartzite (Ranalli 1995).

In contrast to the elastic and plastic models, the viscoelastic model involves time dependence due to the flow of material and heat. Results are obtained by integrating the combined momentum and heat equations until the dyke has solidified. Beyond this time, all deformations are assumed to cease. In order to calculate the heat transport from the dyke into the surrounding host rock, it is clear that for this model the material within the dyke must be taken into account. However, as we are not interested in details such as flow or convection within the dyke, we use a numerical simplification by modelling the liquid dyke as an elastic material with very low moduli (this numerical trick is introduced because of the constraints of the finite element code which requires a mechanical material to 
be present in regions where the heat equation is to be solved). The magma overpressure is applied as a boundary condition at the dykehost rock interface as in the elastic and plastic models. If the effective elastic moduli of the liquid magma are sufficiently low ( $10^{-6}$ times the host rock moduli), then the effect of the dyke material on the surrounding mechanics is negligible and the condition on the host rock is the normal stress due to the overpressure as desired. Care is taken that the magma density and hence the specific heat remain constant throughout the calculation (despite the elastic nature of the volume change inside the dyke). The energy equation (Turcotte \& Schubert 2002)

$\frac{\mathrm{d} T}{\mathrm{~d} t}=\kappa \nabla^{2} T$

is solved with a constant thermal diffusivity of $\kappa=1.3 \times 10^{-6} \mathrm{~m}^{2} \mathrm{~s}^{-1}$ for the solid host-rock and $\kappa=0.98 \times 10^{-6} \mathrm{~m}^{2} \mathrm{~s}^{-1}$ throughout the liquid dyke (Clauser \& Huenges 1995). Magma intrudes the hostrock at an initial temperature of $1200^{\circ} \mathrm{C}$. The integration is stopped when the dyke has completely solidified, which we assume is the case when the solidus temperature $T_{s}=1000^{\circ} \mathrm{C}$ has been reached.

\subsection{Comparison with dyke thickness observations}

We show not only a general overview of the model results, but also provide a best fit to observational dyke thickness data in order to evaluate the models. For this purpose, we use the Rum Island dyke data set of Daniels et al. (2012). The island of Rum, located about $30 \mathrm{~km}$ off the west coast of Scotland, is the remnant core of a volcanic complex that was active $65 \mathrm{Myr}$ ago and intruded in a preexisting formation of Torridonian sandstone and shale (Emeleus \& Hudson 1997; Nicoll et al. 2009). During this period, several episodes of igneous intrusion have formed families of dykes with different orientations and compositions. The data set we are using comprises thickness measurements of dykes in an NW- to NNWstriking basaltic dyke swarm (Emeleus \& Hudson 1997) dated to $60.53( \pm 0.08) \mathrm{Ma}$ (Hamilton et al. 1998). Daniels et al. (2012) report 1068 thickness measurements from 41 dykes with thickness:length aspect ratios between 1:11 and 1:449. The observed dykes are all rather small with maximum recorded lengths of $47.6 \mathrm{~m}$ and maximum thickness of $0.62 \mathrm{~m}$. These dykes are probably not individual dykes but rather segments of a single, longer dyke (Daniels et al. 2012). The calculated overpressures for a given dyke aperture are expected to be lower by a factor of up to 5 for an intrusion that is a segment of a longer dyke instead of a solitary dyke (Tada et al. 2000; Daniels et al. 2012). However, the host rock between the dyke segments is largely intact, indicating that the dyke segment tips were held together by the local strength of the surrounding rock. We concede that the effect of neighbouring segments may have some influence on the results, but complete dyke thickness profiles are scarce and we are limited to the data that are available.

In this paper we use three representative Rum Island dykes, specified as dyke A, B and C (which are the same as those in Daniels et al. (2012), figs 3A-D), and use these as a guide to evaluate the dyke profiles obtained from the different rheological models. Dyke dimensions (from model calculations and from measurements) have been normalized by their overall length (tips are located at 0.5 and -0.5 ) in order to facilitate comparison between data and models of different spatial scales.

One of main goals of this study is to estimate the required overpressures for our rheological models which result in equilibrium thicknesses and shapes similar to those of natural dykes. In order to quantify the fit of our model results to dyke thickness observations, we use the $R^{2}$-criterion,

$R^{2}=1-\frac{\sum_{i}\left(f_{i}-y_{i}\right)^{2}}{\sum_{i}\left(f_{i}-\bar{y}\right)^{2}}$

where $y_{i}$ is a thickness measurement at a particular position along the dyke, $f_{i}$ is a the model estimate of the thickness at the same position, and $\bar{y}$ is the mean value of thicknesses measurements. $R^{2}$ is defined between 0 and 1 where a value of 1 represents a perfect fit between the model and the data. We note that different authors use different definitions of $R^{2}$, and as a result our computed values of $R^{2}$ are lower than those of, for example, Daniels et al. (2012). The bestfitting model is determined by varying the magma pressure until a maximum in $R^{2}$ is found. In principle, there is a possibility of local maxima in the fit which are different from the global maximum. However, this does not appear to be the case for the given data and models, as was verified by testing different starting guesses for the overpressure.

Since purely elastic dyke solutions are perfectly elliptical, while observations of dyke thickness indicate more rectangular shapes, we find it useful to define a parameter $m$ which serves as a simple scalar measure of the shape. Parameter $m$ is defined by an equation closely related to that of an ellipse,

$\left(\frac{x}{a}\right)^{\frac{2}{m}}+\left(\frac{y}{b}\right)^{\frac{2}{m}}=1$

where $a$ is the half-length of the dyke and $b$ its maximum halfthickness. When $m=1$, the definition of an ellipse is recovered, while for $m \rightarrow 0$, the shape approaches that of a rectangle. Obviously, a single parameter cannot describe the complexities of real dyke thickness profiles such as the overall variability or the inherent asymmetries. But since in this study we are not interested in these complexities, we find that $m$ quantifies the observed shapes quite well, and we use plots of $m$ to present summaries of large numbers of model results. For the natural dykes $\mathrm{A}, \mathrm{B}$, and $\mathrm{C}$ of the Rum island data, we find best-fit values of $m_{A}=0.50, m_{B}=0.50$, and $m_{C}=0.59$, indicating that these dykes are all somewhere in the middle between elliptical and rectangular shapes.

\section{RESULTS}

Results from our rheological models which provide the best fit to observational dyke thickness data are compiled in Table 1 and compared to results from the linear elastic model, which are calculated using constant shear and bulk moduli of $15.4 \mathrm{GPa}$ and $21.3 \mathrm{GPa}$, respectively. We focus on the results from our axisymmetric models as we believe that these models are more realistic than the geometry of infinite dyke extent in the third dimension. For the Cartesian 2-D models, the estimated overpressures are typically 10 to 30 per cent lower than those of the axisymmetric models. In the Cartesian setup, we also obtain more rectangular dyke shapes with parameter $m$ reduced by around 10 to 15 per cent compared with equivalent axisymmetric models.

\subsection{Elasticity with pressure-dependent moduli}

For the reference model with pressure-dependent moduli (model Wref), we estimate required overpressures of $418 \mathrm{MPa}$ for dyke A, $817 \mathrm{MPa}$ for dyke B, and $1504 \mathrm{MPa}$ for dyke C (Table 1 and Figs $4 \mathrm{a}-\mathrm{c}$ ). These overpressures are about 10 per cent lower than the corresponding values for the elastic model with constant moduli. For this set of models, parameter $m$ is around 0.93 for all three 
Table 1. Estimated values for required overpressure and shape parameter $m$ calculated from all the rheological models and for the three tested Rum dykes A, B and C. Values in between parenthesis represent the goodness-of-fit between the model and data at the estimated required overpressure.

\begin{tabular}{|c|c|c|c|}
\hline & \multicolumn{3}{|c|}{ Required overpressure in $\mathrm{MPa}, m$ parameter, $\left(R^{2}\right)$} \\
\hline & Dyke A & Dyke B & Dyke $\mathrm{C}$ \\
\hline Elastic & $466,1,(0.21)$ & $887,1,(0.28)$ & $1617,1,(0.31)$ \\
\hline \multicolumn{4}{|c|}{ Elastic with pressure-dependent moduli } \\
\hline Wref & $418,0.93,(0.30)$ & $817,0.93,(0.36)$ & $1504,0.93,(0.39)$ \\
\hline Wweak & $360,0.72,(0.44)$ & $720,0.72,(0.47)$ & $1200,0.72,(0.42)$ \\
\hline Wstrong & $441,0.97,(0.25)$ & $852,0.97,(0.31)$ & $1567,0.97,(0.34)$ \\
\hline \multicolumn{4}{|c|}{ Plastic, $\alpha=0$} \\
\hline P20 & $74,0.84,(0.42)$ & $92,0.90,(0.42)$ & $116,0.96,(0.39)$ \\
\hline $\mathrm{P} 100$ & $218,0.68,(0.50)$ & $269,0.74,(0.50)$ & $326,0.80,(0.53)$ \\
\hline $\mathrm{P} 150$ & $283,0.67,(0.50)$ & $354,0.70,(0.52)$ & $429,0.76,(0.54)$ \\
\hline \multicolumn{4}{|c|}{ Plastic, depth $=10 \mathrm{~km}$} \\
\hline DP0 & $215,0.62,(0.52)$ & $264,0.66,(0.53)$ & $322,0.72,(0.54)$ \\
\hline DP02 & - & - & - \\
\hline DP04 & $440,0.83,(0.32)$ & $764,0.78,(0,41)$ & $1365,-,(0.49)$ \\
\hline DP06 & $447,0.92,(0.29)$ & $816,0.87,(0.38)$ & $1424,-,(0.45)$ \\
\hline
\end{tabular}

(a)

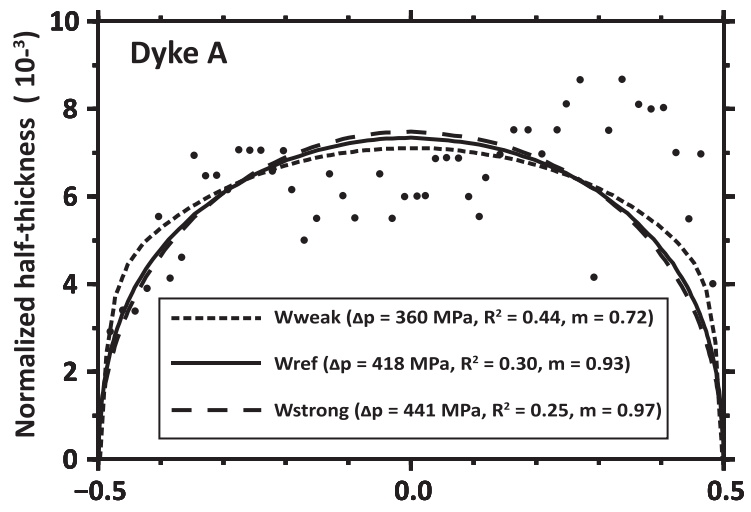

Wweak

(b)

Normalized dyke length

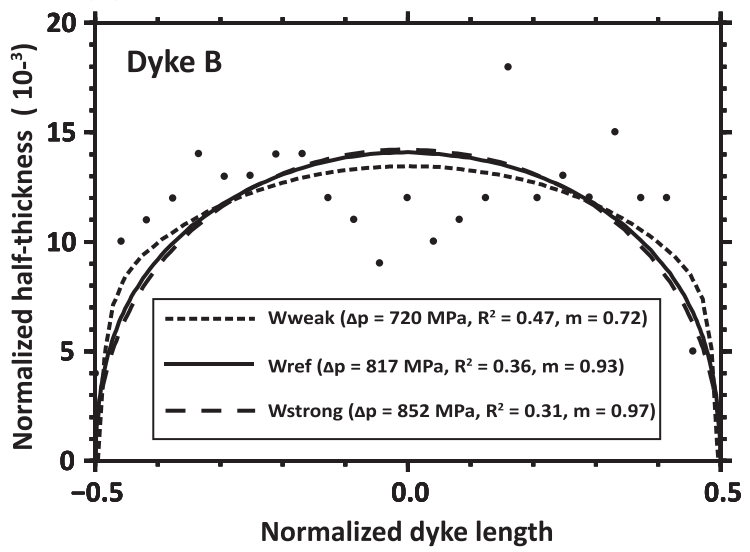

(c)

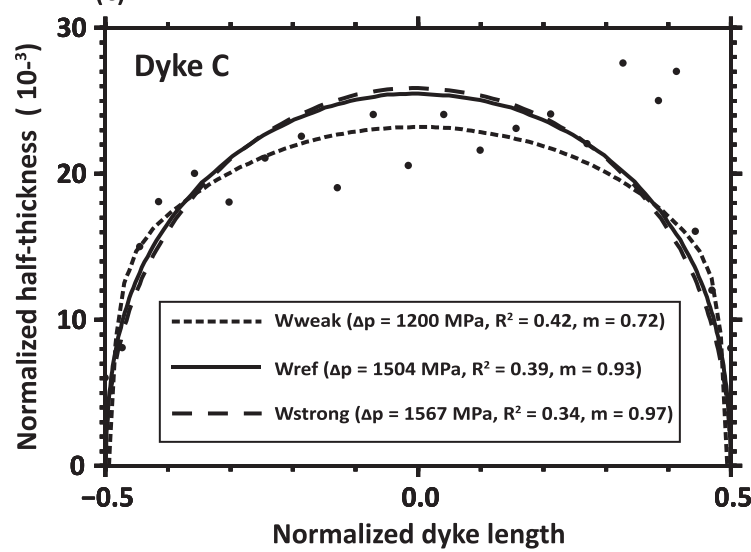

Figure 4. Half-thickness of dyke as function of distance along the dyke, both normalized by dyke length. The dots denote measurements (Daniels et al. 2012, from) from three dykes on the island of Rum (A, B and C). The continuous curves are the best-fit elastic models with pressure-dependent moduli. For each dyke, the three model results correspond to the three different extrapolations for the elastic moduli illustrated in Fig. 2. Required overpressure for the best-fit model as well as the goodness-of-fit $\left(R^{2}\right)$ are indicated in the figure. For additional data, see the text and Table 1.

dykes, indicating that there is a modification of dyke shape towards a more rectangular shape, but that the modelled dykes are still more elliptical than the natural dykes. For the model with greater reduction of the elastic moduli (model Wweak), the required overpressures are about 20 per cent lower than for the reference model (Wref), or about 30 per cent lower than the elastic model with constant moduli. For these models, parameter $m$ is about 0.72 for all three dykes. In contrast, the model with only a moderate 
(a)

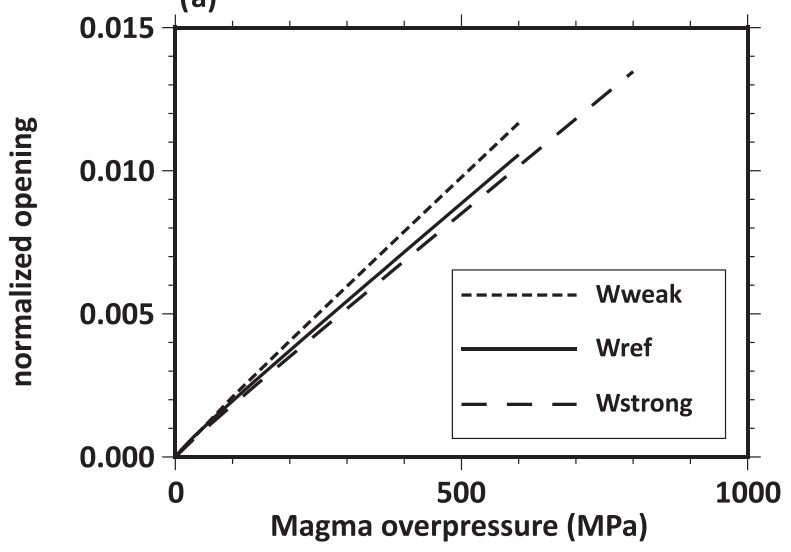

(b)

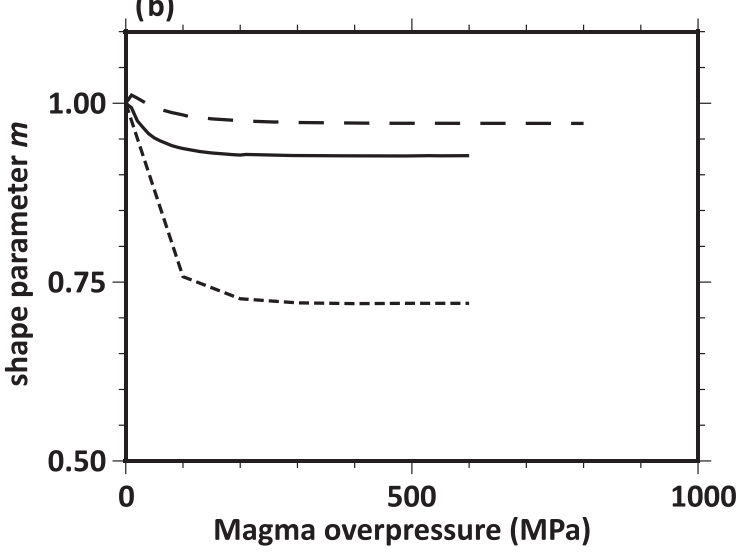

Figure 5. Results from elastic model with pressure-dependent moduli. (a) Normalized maximum opening (at centre of dyke), and (b) shape parameter $m$ as function of overpressure for the three extrapolations of the elastic moduli shown in Fig. 2. Dykes become only slightly thicker but significantly more rectangular $(m<1)$ for the most strongly pressure-dependent model (Wweak).

reduction of the elastic moduli (model Wstrong) results in only a small reduction in the overpressure of about 5 per cent relative to the elastic model with constant moduli, and parameter $m \approx 0.97$ remains rather close to unity. The goodness-of-fit as measured by $R^{2}$ shows a progressive improvement from the model with constant moduli $\left(R^{2} \approx 0.30\right)$ to the model with the greatest rheological weakening $\left(R^{2} \approx 0.44\right)$.

Figs 5(a) and (b) shows parameter $m$ and dyke opening as a function of overpressure for models Wweak, Wref and Wstrong. At low overpressures of $0 \mathrm{~Pa}$ to $200 \mathrm{MPa}$, parameter $m$ decreases from 1.0 to 0.72 for Wweak, to 0.93 for Wref, and to 0.97 for Wstrong. Comparison of the three models shows that an increase in the overpressure generally produces more rectangular dykes, and the most rectangular dykes with the lowest value of $m$ are obtained for model Wweak. For increases in overpressure above $200 \mathrm{MPa}$, the inflated cracks more or less maintain their shape, and the value of $m$ remains relatively constant. In all three models, the maximum opening of the inflated crack increases approximately linearly as a function of overpressure. For a given overpressure, models with greater reduction in the elastic moduli exhibit greater dyke thicknesses, and the thickness increase for the rheologically weakest model is about 25 per cent relative to the elastic model with constant moduli. From the stress field (not shown, but generally similar to the stress field for constant elastic moduli), we conclude that the spatial domain in which the elastic moduli are significantly reduced is small and confined to a region ahead of the dyke tips. Apparently, a relatively modest local reduction of the elastic moduli (by a factor of about 4 to 8 ) confined to a small region of tensile stresses results in a significant change in the dyke shape, but only in a relatively small increase in dyke thickness. A greater reduction in the elastic moduli would probably lead to a better model fit to the data, but we did not test such functions of $G(p)$ and $K(p)$ because they are not supported by experimental evidence, and because the resulting strains are probably well beyond the elastic limit.

While we are not aware of any natural process that reduces only one of the elastic moduli while leaving the other unaffected, we note that the dominant effect on dyke shape and opening comes from the reduction in $G$. A reduction in $K$ alone, by the same proportion, essentially leaves the maximum dyke opening unchanged and causes only a minor blunting of the dyke tips.

\subsection{Plasticity}

To get a broad overview of the potential effects of plastic failure in the host rock, we ran one set of models without pressure dependence for different values of rock cohesion, and a second set of models with fixed cohesion but with varying dependence on pressure and varying depth. Without pressure dependence $(\alpha=0)$, the DruckerPrager yield criterion is identical with the von Mises criterion. The yield stress $\left(\sigma_{y}=\sqrt{3} k\right)$ was set to 20,100 and $150 \mathrm{MPa}$ for models P20, P100 and P150, respectively. The results are summarized in Table 1 and Figs 6(a)-(c). Especially for low values of cohesion, we see that plasticity has a dramatic effect on the results. The overpressure required to form dykes of similar thickness as the three dykes on Rum is reduced by a factor of about 10 relative to the elastic reference model. Moreover, it is observed that the variation in the overpressure required to match the three thickness observations has decreased significantly. For the elastic reference model, the overpressures range from 466 to $1617 \mathrm{MPa}$ (a factor of 3.5), while for model P20, the overpressures range from 74 to $116 \mathrm{MPa}$ (a factor of 1.6). For greater values of cohesion (models P100 and $\mathrm{P} 150$ ), the overpressures that are required to match the dyke thicknesses observed on Rum are greater by a factor of 3 to 4, but these overpressures are still significantly lower than those for the elastic reference model. Fig. 7(a) shows the variation of dyke opening as a function of magma overpressure. At low values of overpressure, plastic flow does not significantly affect the results because the shear stresses (given by $J_{2}$ ) are almost everywhere lower than the yield stress. In this regime, the models are essentially elastic. Significant divergence from the straight line that signifies elastic behaviour occurs around overpressures of $30 \mathrm{MPa}$ for model P20, $140 \mathrm{MPa}$ for model P100 and $200 \mathrm{MPa}$ for model P150. Plastic deformation also has a strong effect on the shape of the dykes which changes to a more rectangular form as evidenced by parameter $m$ (Table 1). For model P20, $m$ ranges from 0.73 to 0.91 . However, while the low overpressure of model P20 best matches overpressure estimates based on independent observations, the shapes of all three Rum dykes are best fit by model P150 as indicated by the high values of $R^{2}$. Fig. 7(b) shows that parameter $m$, which quantifies the shape, is not a simple monotonic function of overpressure. Instead, there is a minimum value of $m$ at some value of overpressure which is different for different values of cohesion. For all three models (P20, P100 and P150), the overpressure required to match the dyke 

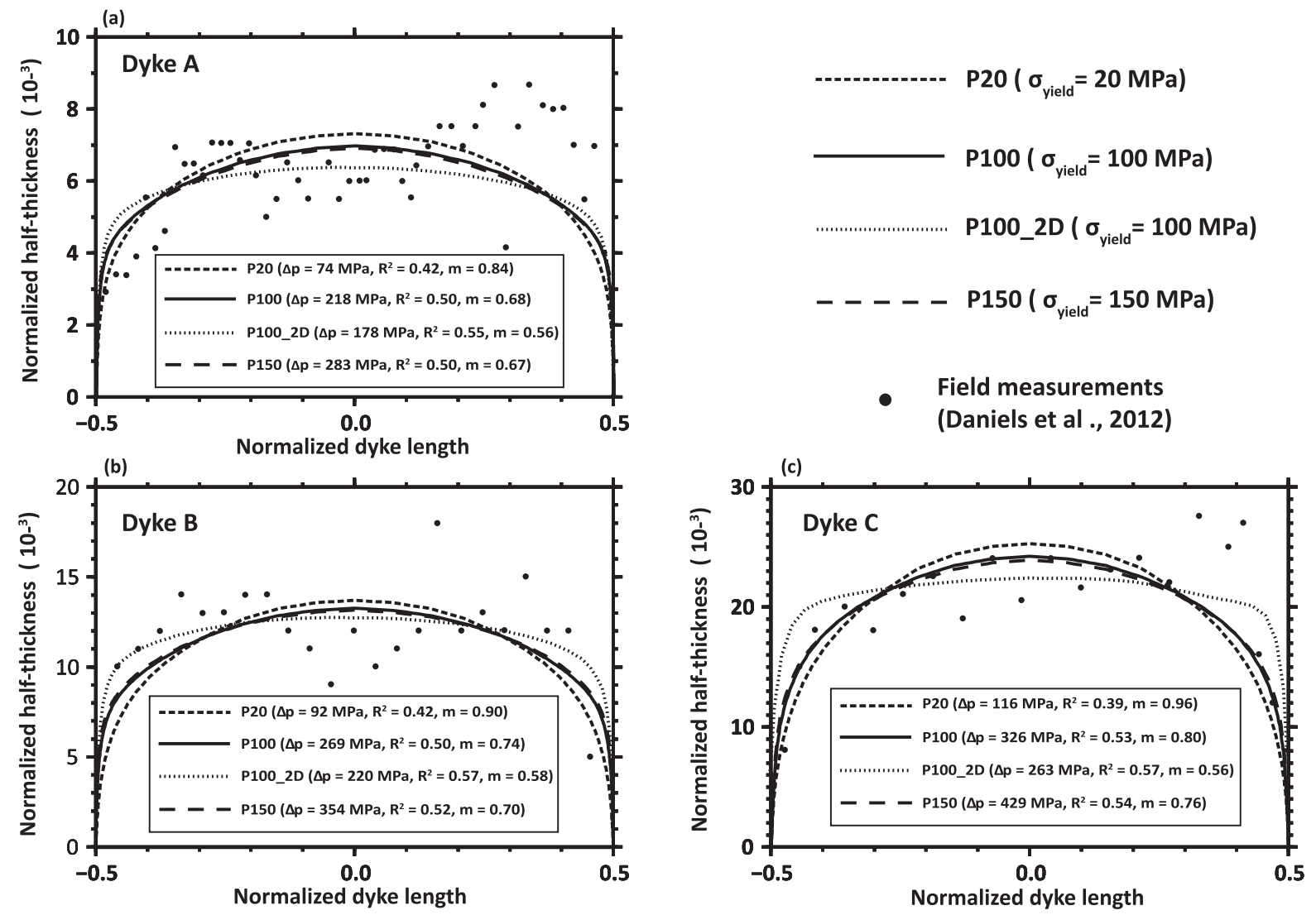

Figure 6. Half-thickness of dyke as function of distance along dyke, both normalized by dyke length. Field measurements for the three dykes on Rum (A, B and C) are denoted by dots. The continuous curves are the best-fit plastic models without pressure dependence $(\alpha=0)$ and with different yield stress $\left(\sigma_{y}=k \sqrt{3}\right)$. Overpressures are most strongly reduced for models with low yield stress, while dyke shape deviates most strongly from the initial ellipse for models with higher yield stress (e.g. shape parameter $m \approx 0.7$ for model P150). We also show results for a model with plane-strain configuration in the third dimension (model P100-2D) instead of the axial symmetry condition of the other models. The plane-strain dyke is much more rectangular $(m<0.6)$ because there is less material around the dyke tips relative to total dyke volume which has to be deformed.
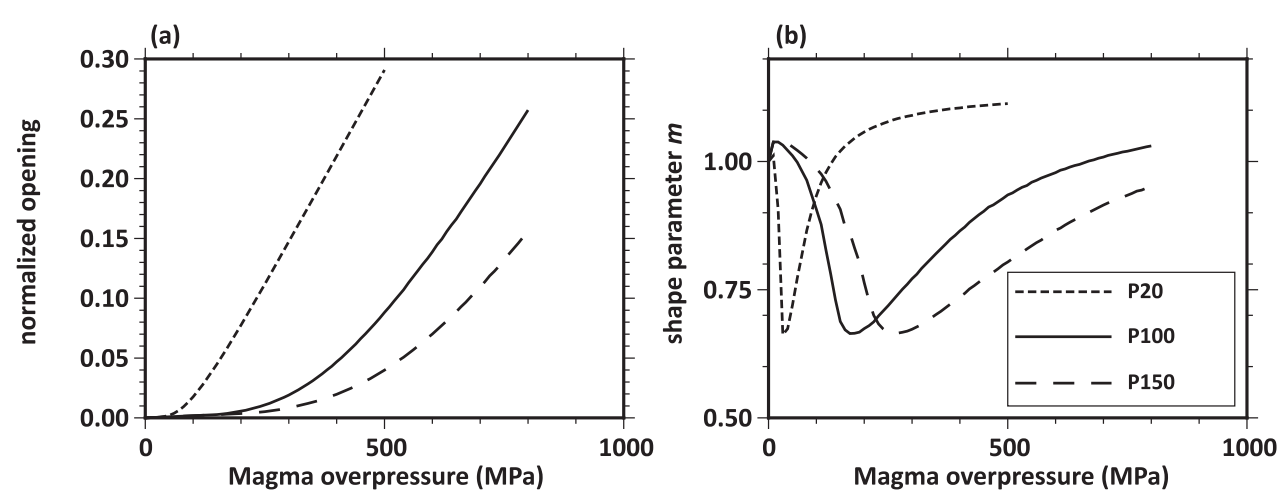

Figure 7. Results from plastic models without pressure dependence for three different values of yield stress $\left(\sigma_{y}=k \sqrt{3}\right.$ ). (a) Normalized maximum dyke opening (centre of dyke), and (b) shape parameter $m$ as functions of overpressure. In the relevant range of overpressure, approximately between the host-rock yield stress and the maximum realistic overpressure of $c a$. $100 \mathrm{MPa}$, dyke opening is enhanced by about one order of magnitude. Dyke shape initially becomes more rectangular as overpressure is increased, but for all models a minimum value of $m \approx 0.65$ is reached beyond which $m$ again increases. The reason for this appears to be that localized deformation near the dyke tips at the onset of failure leads to a more rectangular dyke, while broadly distributed failure at higher overpressure results in a regression towards an ellipse.

observations is greater than the $m$-minimum. But for models P100 and $\mathrm{P} 150, m$ is lower than for $\mathrm{P} 20$, and hence it is the most rectangular dyke models that best fit the observations. The reason for the increase in $m$ for high overpressure is that the region of plastic failure is no longer limited to the immediate vicinity of the dyke tip, but grows in size to cover much of the dyke's surroundings. In this stage, the dyke becomes more elliptical again as overpressure increases.

In a second set of models, we kept the cohesion fixed at $k=57.7 \mathrm{MPa}$ and varied the pressure dependence determined by $\alpha$. The results are summarized in Table 1 and Fig. 8 . The pressure dependence in the failure criterion affects the results in two ways. 
(a)

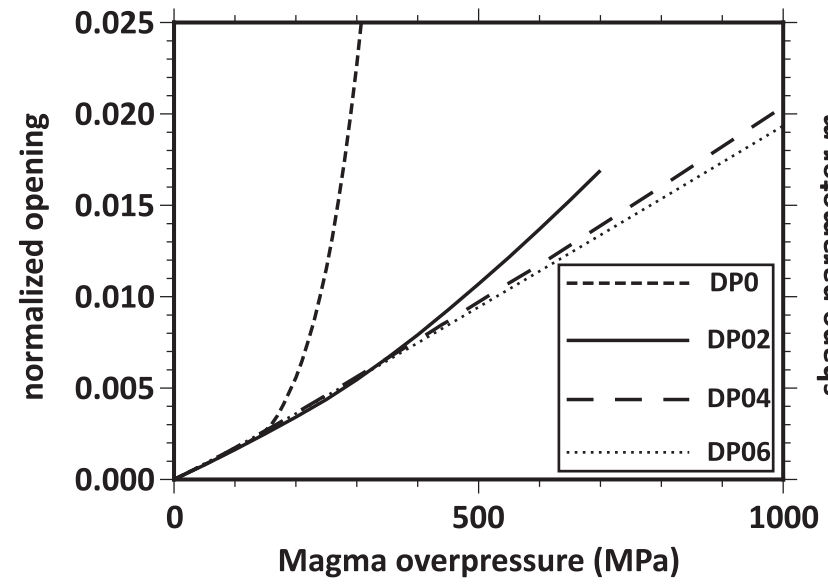

Surface

(b)

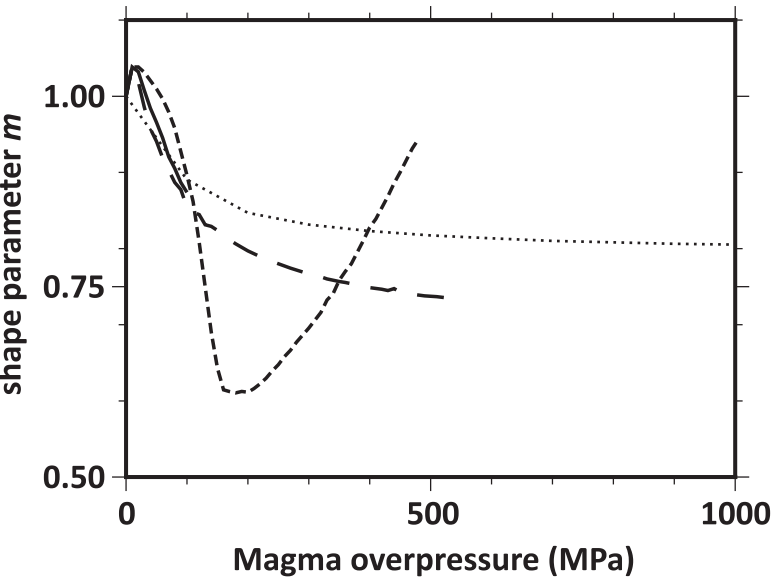

(c)

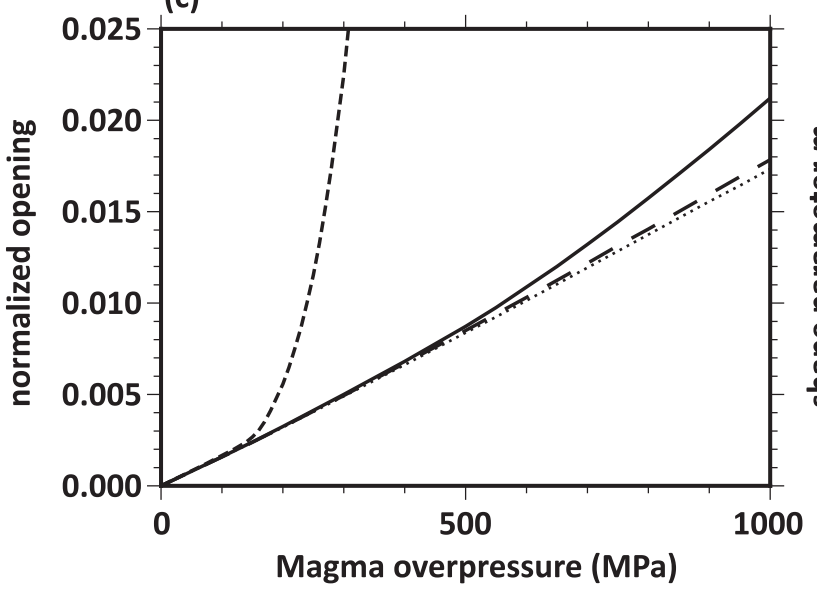

Depth : 5 km (100MPa)

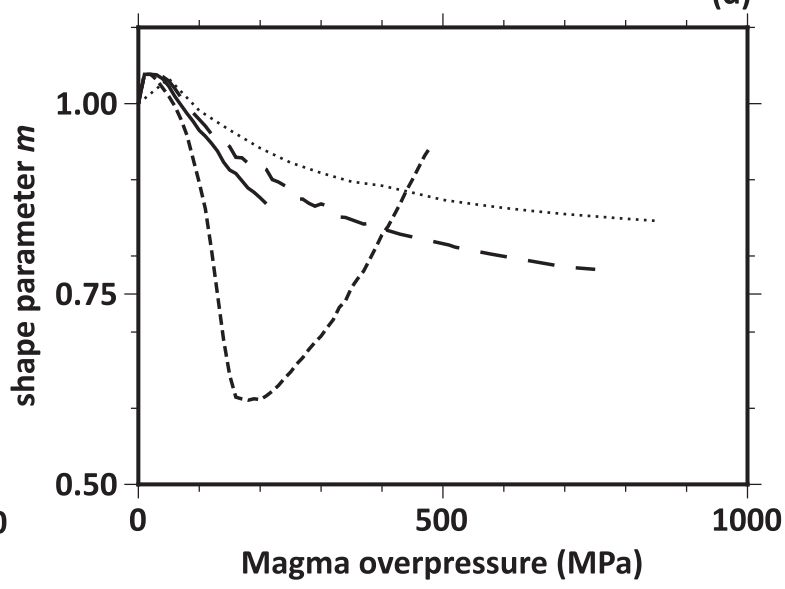

(e)

Depth : 10 km (200MPa)
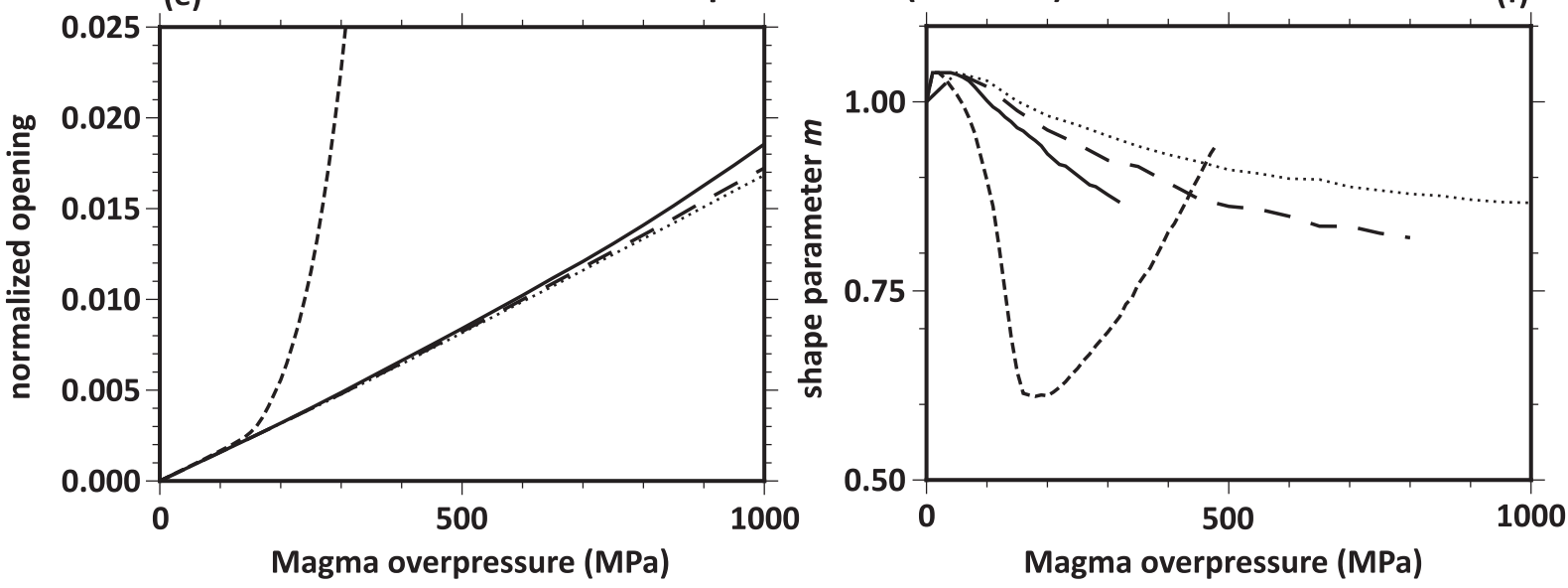

Figure 8. Results from plastic models with different values of pressure dependence $\alpha$ and with cohesion set to $k=57.7 \mathrm{MPa}$. Normalized maximum dyke opening at centre of dyke (panels a, c, e) and shape parameter $m$ (panels b, d, f) for three different depths with corresponding overburden pressure as indicated. The effects of plastic failure decrease markedly with increasing $\alpha$ and with increasing depth, especially when compared with the pressure-independent models.

The first effect is that the static overburden causes an increase in the cohesion of the material. The second effect is due to the dynamic pressure resulting from dyke opening, which mostly causes a decrease in cohesion in the region ahead of the dyke tips. At shallow depth, the tensile stresses around the dyke tips are typically greater than the compressive stresses due to the overburden, thus resulting in a loss of cohesion, or even in negative cohesion. In principle, it should be possible in a numerical model to increase the magma 
pressure sufficiently slowly so that plastic flow keeps regions of zero or negative cohesion from developing. In practice, we found this difficult, and for models with high magma pressure and relatively weak pressure dependence (model DP02 with $\alpha=0.2$ ), we were unable to obtain convergent solutions (Table 1 and Fig. 8). However, we were able to compute solutions for models without pressure dependence (models P20, P100 and P150), for models with stronger pressure dependence (model DP04 with $\mu=0.4$ ), and for model DP02 with relatively low magma pressure. Moreover, since standard rock experiments consistently indicate relatively strong pressure dependence $(\alpha \approx 0.85$ (Turcotte $\&$ Schubert 2002)), the lack of results in this particular regime does not significantly hamper our ability to draw conclusions about the elastoplastic models.

The pressure dependence in plasticity fundamentally modifies the model outcome. One change regards the dyke opening and hence the magma overpressure required to match the thickness observations of natural dykes. Even a rather modest pressure dependence given by $\alpha=0.2$ (model DP02) brings about an abrupt change in the nature of the model outcome relative to the pressure-independent results (model DP0, which is identical to model P100). Additional tests with very low pressure-dependence $(\alpha=0.01$; results not shown) indicate that there exists a smooth continuum of curves in the plot of dyke opening versus overpressure between models DP0 and DP02 (Fig. 8). But for the geologically more relevant $\alpha$-values shown in Fig. 8, the pressure-dependent models DP02, DP04 and DP06 cluster fairly closely together and are rather similar to the purely elastic reference model with constant elastic moduli. The second observation regards the shape of the dykes. While the dyke opening is only mildly affected in the pressure-dependent plastic models, the shape parameter $m$ shows that the dykes are much more rectangular than the elliptical reference model. A similar conclusion can be drawn from the values of $R^{2}$, which show that the fit of the models to the natural dykes on Rum is improved, albeit not by as much as in the pressure-independent plastic models.

Varying depth only has a minor effect on the plastic results. Generally, dyke opening decreases with depth and the shape becomes more elliptical $(m \rightarrow 1)$. The variation is most pronounced for models with low values of $\alpha$, while models with higher $\alpha(\alpha>0.4)$ largely converge towards the elastic solution with increasing depth.

Overall, the results show that plasticity with low cohesion (low $k$ ) and with low pressure-dependence (low $\alpha$ ) causes a large increase in dyke opening, or alternatively a large decrease in the magma overpressure required to match dyke thicknesses observed in nature. Increasing the cohesion $k$, the pressure-dependence $\alpha$, or the rock overburden in pressure-dependent plastic models results in a decrease in dyke thickness. All plastic models exhibit an improvement in the fit of the dyke shape when compared with natural dykes. The fit is best for models without pressure dependence.

\subsection{Viscoelasticity}

The viscoelastic system is different from the purely elastic and elastoplastic systems because heat conduction and viscous creep introduce time dependence into the problem. Since the diffusion length scale is proportional to the square root of time, while the viscous displacements scale linearly with time, the thermally controlled viscoelastic problem is dependent on the size of the dyke. As will be seen, unless the initial host-rock temperature is close to the melting temperature, viscous flow becomes significant only for dykes greater than about a metre in thickness. The dykes on Rum which we use to test our models are only a few centimetres thick. Since the viscoelastic model for such dykes is essentially identical with the linear elastic reference model, we do not show the corresponding fits. Instead, we focus on the systematics of the viscoelastic model and its dependence on host-rock temperature and initial dyke size. The viscoelastic rheology is, at least to first order, independent of pressure so that the results are valid regardless of lithostatic overburden.

In a first set of simplified experiments (results not shown), we computed dyke opening after a fixed length of time $\left(t_{\text {final }}=10^{7} \mathrm{~s}\right)$ in a medium with constant elastic and viscous parameters. When the viscosity is high, corresponding to temperatures of $0{ }^{\circ} \mathrm{C}$ to about $150{ }^{\circ} \mathrm{C}$ for the quartzite rheology chosen, viscous deformation is negligible and the results are nearly identical to those of the purely elastic model. When the constant viscosity is decreased to $10^{16}$ $10^{17} \mathrm{~Pa} \mathrm{~s}$ or lower (corresponding to temperatures of about $200^{\circ} \mathrm{C}$ or higher), significant viscous flow occurs, and the dyke width is increased by about a factor of 10 (for $\eta \approx 10^{16} \mathrm{~Pa}$ s) relative to the purely elastic case. For all cases with constant viscosity, the dyke remains perfectly elliptical. The analytical solution for a uniformly pressurized elliptical void in an elastic medium with constant moduli is (Costa et al. 2007)

$$
\begin{aligned}
& a(z)=a_{0}(z)+\frac{\Delta P}{2 G}\left[2(1-v) b_{0}(z)-(1-2 v) a_{0}(z)\right] \\
& b(z)=b_{0}(z)+\frac{\Delta P}{2 G}\left[2(1-v) a_{0}(z)-(1-2 v) b_{0}(z)\right]
\end{aligned}
$$

where $a$ and $b$ are the semi-major and semi-minor axis, $a_{0}$ and $b_{0}$ are their initial values, $v$ is Poisson's ratio and $\Delta P$ is overpressure. The analogous viscous solution is obtained by setting $v=0.5$, and replacing $G$ with the viscosity $\eta$ and $a$ and $b$ on the left-hand side of the equations with the corresponding time derivatives. An initially elliptical dyke will thus always remain elliptical, but will with time grow in thickness towards a circular shape.

Next, we move one step closer to the complete thermomechanical solution by including heat conduction and temperaturedependent viscosity, but we still terminate all models at the same time $t_{\text {final }}=10^{7} \mathrm{~s}$. Since the dyke before viscous deformation (i.e. initial void plus elastic deformation) is of the order of a few metres thick, the total heat content of the magma is relatively small and causes significant heating only within a small volume of host rock which is similar to the dyke volume itself. The elongate geometry of the dyke results in a wider high-temperature halo along the sides of the dyke than around the dyke tips. However, shear stresses are nearly zero along the dyke walls so that the increase in temperature there is inefficient in enhancing deformation. As a result, the opening of the dyke is largely unaffected by the viscosity reduction due to heat escaping from the magma. However, even though heat conduction is geometrically inefficient in producing a temperature increase at the dyke tip, the small temperature change there is nonetheless significant because the stresses are strongly concentrated directly at the dyke-host rock interface at the dyke tip. The viscosity drop in this small volume of rock is sufficient to cause a significant reduction in parameter $m$, indicating that the dyke changes from an ellipse to a more rectangular shape. It is also this viscosity decrease at the dyke tip rather than that along the dyke walls which causes the observed small increase in dyke opening.

The complete viscoelastic solution additionally includes the effect of the time required for dyke solidification. As the initial temperature of the surrounding host rock is varied, the solidification time varies as well. For an increase in initial temperature $T_{\text {init }}$ from 0 to $270{ }^{\circ} \mathrm{C}$, the solidification time increases about eight-fold from 


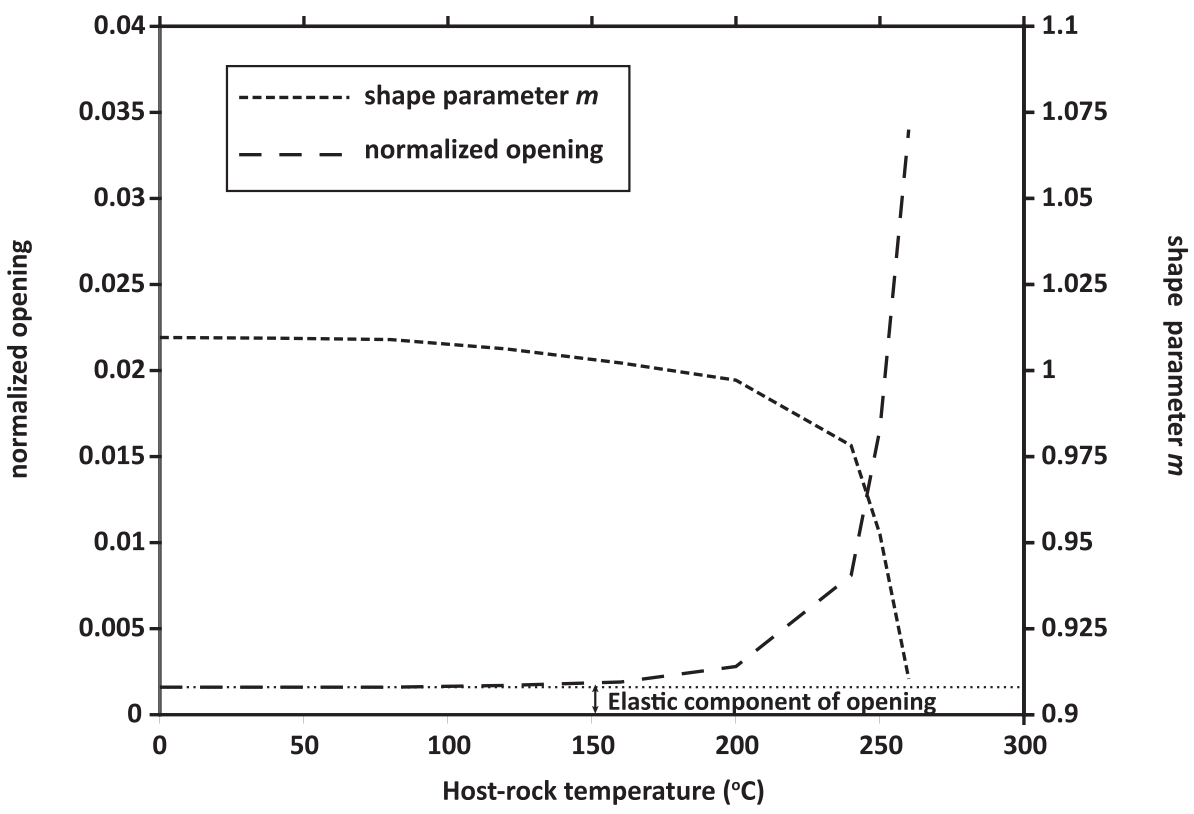

Figure 9. Results from viscoelastic models. Normalized maximum dyke opening and shape parameter $m$ as functions of initial host-rock temperature for a dyke of length $L=2000 \mathrm{~m}$ and initial thickness $d=2 \mathrm{~m}$. In comparison, the elastic contribution to the total dyke opening is also indicated. Overpressure is held constant at $\Delta p=100 \mathrm{MPa}$, and the simulation is stopped when the entire dyke is considered solidified at $T_{\text {solidus }}=1000^{\circ} \mathrm{C}$. For low background temperatures, the heat conducted from the dyke into its surroundings is insufficient to cause significant viscous flow during the solidification time. Already at relatively modest background temperatures $\left(T \approx 200^{\circ} \mathrm{C}\right)$ significant flow occurs, and for the quartzite host-rock rheology used, thermal runaway occurs at temperatures $T<300^{\circ} \mathrm{C}$ due to the influx of heat into the dyke as the dyke widens at constant overpressure.

$3.0 \times 10^{6}$ to $2.3 \times 10^{7} \mathrm{~s}$. The total viscous deformation increases with the time available for the flow, and thus the dykes in hotter surroundings grow thicker not only because of the reduction in viscosity, but also because of the longer solidification time. The solutions to the complete viscoelastic problem for different background temperatures are summarized in Table 1 and in Fig. 9.

Since the thermal diffusion time and the viscous deformation scale differently with the spatial dimensions of the problem, the size of the dyke is an important parameter in the thermomechanically coupled system. The results for dykes of different size (i.e. different initial length and thickness) are shown in Fig. 10. As long as the opening of the dyke due to viscous effects is small, the dyke opening scales approximately quadratically with the length scale. This behaviour is expected because the timescale of thermal diffusion and hence the solidification time scale with length squared. However, for greater values of dyke opening, the increase is more rapid. This effect is due to the additional inflow of hot magma into the expanding dyke. In our models, we choose to maintain a constant pressure at the dyke walls at all time, which is balanced by an increase in the magma volume (at constant temperature). This additional heat input extends the cooling time, which results in a positive feedback with further dyke growth.

\section{DISCUSSION}

From a dynamical standpoint, the three host-rock rheologies tested in this study are interesting because they all enhance deformation and thus facilitate dyke opening, but they do so in different ways. The elastic rheology with pressure-dependent moduli enhances both volumetric and shear deformation in regions of tension or low compression. All deformations are elastic and thus in principle recoverable, but for our model setup this aspect is not relevant because the magma pressure never decreases and thus all deformations persist after magma solidification. The plastic rheology amplifies shear deformation in regions of high shear stress (for the von Mises yield criterion) or in regions where a combination of shear and tension is high (for the pressure-dependent Drucker-Prager criterion). The total strain can become much greater for the plastic material than for the elastic one because deformation continues as long as the yield criterion is fulfilled. The viscoelastic rheology also enhances shear deformation, but only in regions where the temperature is relatively high. As for the plastic rheology, the viscous strains can become large provided that the deformation has sufficient time to develop.

When applied to the dyke problem, the three rheologies yield fundamentally different results. The elastic rheology is the only rheology that allows volume changes. It was observed that the reduction in the bulk modulus, which enhances volume changes where pressures are low, only has a minor effect on dyke opening and no appreciable effect on the shape of the dyke. A reduction in the shear modulus, which enhances only shear deformation, has a greater effect on dyke opening and also a significant effect on dyke shape by blunting the dyke ends and making the overall shape more rectangular. However, given the magnitude of the pressure-dependence of $K(p)$ and $G(p)$ of the sandstone rheology used (which is typical of fairly porous rock types), the additional dyke opening due to the higher compliance is only a few per cent relative to the elastic reference model with constant moduli. Even at very low confining pressures corresponding to less than $1 \mathrm{~km}$ of overburden, reduction of the effective elastic moduli due to open pores and cracks is not sufficient to explain the observed large dyke thicknesses, assuming that the magma overpressure in dykes is generally limited to a few tens of MPa. On the other hand, the pressure-dependent moduli can explain the observed dyke shapes which are typically somewhere between an ellipse and a rectangle, but only if the effect is close to its maximum, that is, under near-surface conditions and for highly porous host rock. 


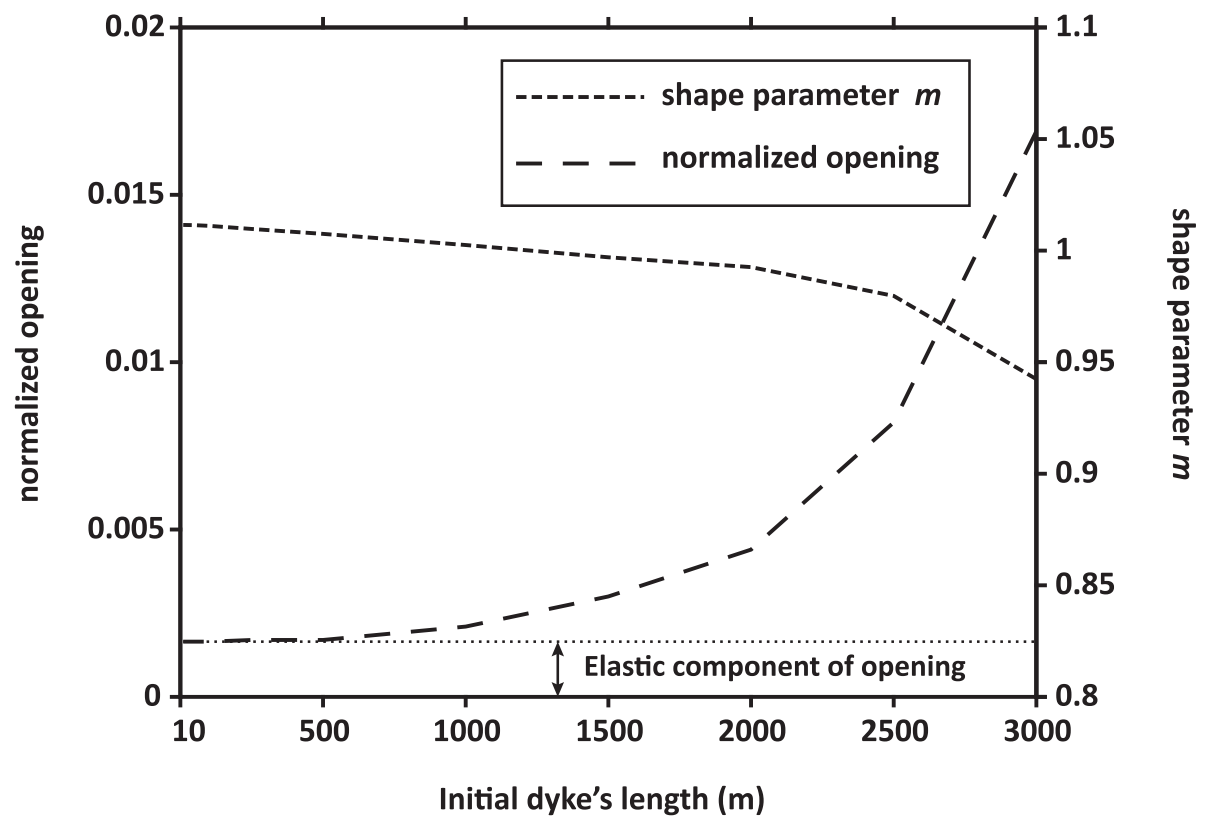

Figure 10. Results from viscoelastic models. Normalized maximum dyke opening and shape parameter $m$ as functions of the length of the dyke. The elastic contribution to the total dyke opening is also indicated. Initial dyke aspect ratio is held constant so that initial dyke thickness scales with dyke length. Overpressure is set to $\Delta p=100 \mathrm{MPa}$ and background temperature is $T=240^{\circ} \mathrm{C}$. The timescale of dyke solidification is proportional to the square of the length scale of the system. For small dykes, the solidification time is short and the system is essentially elastic. Significant viscous flow only occurs for larger dykes with longer solidification times. For the given background temperature $T=240{ }^{\circ} \mathrm{C}$ and the given quartzite rheology, dykes thicker than about $2 \mathrm{~m}$ will be subject to viscous deformation of the host-rock.

The elastoplastic rheology has a much greater potential to affect both dyke opening and dyke shape. Especially when the yield strength is independent of pressure (i.e. the von Mises criterion) and when the cohesion parameter $k$ is low (cohesion $C \approx 20 \mathrm{MPa}$, or $k \approx 12 \mathrm{MPa}$ ), total dyke opening can be many times greater than for the elastic rheology alone. Equivalently, the plastic deformations reduce the magma overpressure required to produce the observed dyke thicknesses by a factor of about 5 to 15 . The dykes that require the highest overpressure in the elastic rheology are subject to the largest pressure reduction due to plasticity, so that all dyke models (model P20 or with even lower cohesion) result in realistic magma overpressures. The elastoplastic rheology also displays the best fit of the dyke shape to the observations, with the high-cohesion models (cohesion $C=150 \mathrm{MPa}$, or $k=87 \mathrm{MPa}$ and without pressure dependence) performing best, although the fit for the other plastic models is nearly as good. If plasticity is to simulate brecciation and frictional sliding of rock, then the pressure-independent von Mises plasticity model is inadequate and pressure dependence must be taken into account, either by using a Mohr-Coulomb criterion or the similar (and numerically more robust) Drucker-Prager criterion used in this study. In this set of models, two mechanisms compete with each other: the lithostatic overburden mostly causes a net increase in the cohesion and thus reduces plastic deformation, while the dynamic pressure around the dyke tips is negative and therefore facilitates plastic deformation. Already at a depth of $10 \mathrm{~km}$, the dominant effect is that of the overburden. It is well-known that the stress concentration at the tip of an ellipse scales with the aspect ratio of the ellipse (Timoshenko \& Goodier 1970). For an aspect ratio of $10^{-3}$ and a modest overpressure of $10 \mathrm{MPa}$, stresses at the dyke tip are of the order of $10 \mathrm{GPa}$. It is clear that even down to great depth plastic failure will occur near the dyke tips even in the most strongly pressure-dependent plasticity models. However, for a lithostatic overburden corresponding to $10 \mathrm{~km}$ depth, the zone of plastic failure surrounding the dyke tips is small relative to the region of failure in the pressure-independent models. On the other hand, because of the dynamic pressure in the Drucker-Prager model, this zone has an effective cohesion of zero and thus cannot support any shear stresses. The total effect is a significant change in dyke shape from ellipse towards rectangle, but the dyke thickness is only modestly increased. It appears that dyke shape is mostly controlled by the resistance to shear motion in the immediate vicinity of the dyke tips, while the total dyke opening is more sensitive to a more broadly distributed resistance to shear.

For plasticity to have a significant effect on dyke opening, the failure criterion must be nearly insensitive to pressure. One possibility is that the mechanism underlying plasticity is of a ductile nature similar to metal plasticity which has no appreciable sensitivity to pressure (Hill 1998). However, given the generally low pressure and temperature conditions, it seems that ductile flow is unlikely except directly at the dyke tip. A more likely possibility is that volatiles escaping from the hot dyke or the dyke-host rock interface penetrate into pre-existing or newly created cracks (Lister 1990; Rubin 1993) and thus reduce the effective normal stress on the sliding surfaces (Jaeger et al. 2009; Turcotte \& Schubert 2002) and possibly also the effective cohesion. If the volatile pressure is similar to the overburden pressure, the effect of the overburden is cancelled (Turcotte \& Schubert 2002), while the effect of the dynamic pressure at the dyke tip remains or is possibly enhanced. We did not test such a model because it would introduce too many unconstrained parameters, but it is expected that its effect on dyke thickness (and shape) would be at least as great as that of the pressure-independent plasticity models.

Viscoelasticity has almost no effect on dyke opening or shape if the background temperature of the host rock is low (i.e. around $0{ }^{\circ} \mathrm{C}$ ). However, the effect increases dramatically with increasing background temperature due to the strong temperature dependence 
of viscosity. For the quartzite rheology used in this study, significant viscous flow commences around $200{ }^{\circ} \mathrm{C}$. For a host-rock of basaltic composition, the viscosity is higher and a background temperature of about $400{ }^{\circ} \mathrm{C}$ is required instead. For a typical continental geotherm, a temperature of $200{ }^{\circ} \mathrm{C}$ occurs at a depth of less than $10 \mathrm{~km}$ and a temperature of $400{ }^{\circ} \mathrm{C}$ at less than $20 \mathrm{~km}$. Active volcanic regions are typically characterized by an elevated geothermal gradient, and the corresponding depth will be significantly shallower. A uniformly low viscosity results in increased dyke thickness but perfectly elliptical shape. Heat flow from the dyke into the surrounding rock only affects a very limited volume of rock surrounding the dyke and is particularly ineffective in heating the zone ahead of the dyke tip, but it is nonetheless the viscosity drop in exactly this region that causes the change in shape in the viscous models because this is where the stresses are highest. Especially for large dykes with greater heat content, this effect is significant and dyke shapes are rather similar to those of the plastic models. As the background temperature is increased, dyke thicknesses for initially large dykes grow without bound in our model due to the applied constant pressure condition at the dyke-rock interface. In nature, the magma supply will typically become exhausted and the pressure at the boundary will diminish.

In general, thickness-to-length ratios of dykes are closely related to the concept of fracture propagation since an influx of magma into a dyke may cause dyke growth either in length or in thickness. In our study, as in many similar studies, the dyke ends are assumed to be fixed so that fracture propagation is suppressed. In physical dykes, the fracture criterion sets a limit on dyke thickness for a given dyke length, with thick and relatively short dykes possible only in materials that are difficult to fracture. The fundamental criterion governing fracture propagation is the well-known Griffith criterion which is based on fracture energetics. A fracture propagates if the elastic strain energy released during an infinitesimal extension of the fracture is greater than the sum of all energies consumed, which include (perhaps predominantly) the free surface energy of the newly created fracture surfaces, but also other losses such as viscous and plastic deformations, heat generation, and elastic waves (Lawn 1993; Hertzberg 2012). Much of the fracture mechanics literature is concerned with cracks in elastic media with inelastic deformations confined to a negligibly small process zone around the crack tips. For these conditions, numerous analytical solutions for the elastic deformations have been derived for different boundary conditions (Hertzberg 2012), and moreover, an approximate equivalence can be established between the critical energy release rate $G_{c}$ of the Griffith criterion and the fracture toughness $K_{c}$ (Lawn 1993). The material toughness is then a material property which measures the material's resistance to fracture propagation. Laboratory measurements show consistently that typical values of fracture toughness of competent rock are around 1-2 MPa m ${ }^{1 / 2}$ (Clifton et al. 1976; Atkinson 1984). On the other hand, the minimum fracture toughnesses inferred from length and thickness data of dykes are much greater, typically 30 $150 \mathrm{MPa} \mathrm{m}^{1 / 2}$ (Delaney \& Pollard 1981; Rubin \& Pollard 1987; Parfitt 1991; Rivalta \& Dahm 2006; Gudmundsson 2009). The discrepancy of about a factor 10-100 between laboratory values and dyke observations is probably due to extensive inelastic deformation in the host rock which is not confined to a negligibly small zone at the dyke tip. If a significant proportion of the deformation is caused by viscous, plastic or frictional processes, then the recoverable strain energy is correspondingly reduced. The Griffith criterion still holds, but less energy is available for fracture propagation. If these processes are not properly accounted for, then the apparent fracture toughness derived from dyke observations may be signif- icantly greater than values measured in the laboratory for known fluid pressures. This explanation was already put forward when the first fracture toughness measurements were carried out (Rubin \& Pollard 1987), but the inelastic processes were never examined further. A quantitative evaluation of the Griffith criterion and the corresponding fracture toughness for the rheologies used here will be provided in a separate study.

\section{CONCLUSIONS}

Host-rock rheology has a significant effect on the thickness and shape of dykes. Overall, this effect is sufficient to explain the disparity in magma overpressure estimates between measurements on natural dykes and previous model results. However, the three rheological mechanisms tested affect dyke thickness and shape in different ways, and they are effective to varying degree throughout the rock column.

Increased elastic compliance due to open cracks and pores in the host rock alters the dyke shape from elliptical towards rectangular and results in a significantly improved fit to thickness data of natural dykes. However, while this rheological effect is well-constrained by experimental studies, the mechanism is limited to the uppermost $1-2 \mathrm{~km}$ of the crust, and it only has a negligible effect on dyke thickness.

Elastoplasticity can have a large effect on both dyke opening and shape, but only if the yield criterion is not strongly dominated by the lithostatic overburden. This could be the case either near the surface where the overburden is low, or if the yield criterion is independent of pressure. Elevated pore pressure due to exsolving volatiles from the magma or from the dyke-rock interface would result in facilitated brecciation of rock at the dyke tip and in a substantial decrease in frictional resistance to slip on the newly created fracture surfaces. If the volatile pressure balances the overburden (note that this corresponds a volatile overpressure of zero), it is conceivable that the plastic yield criterion is effectively independent of pressure, provided that the volatile pressure can penetrate sufficiently deep into the host rock. Under these conditions, plasticity results in a good data fit in terms of dyke shape, and at the same time reduces the required magma overpressure to realistic values of a few tens of $\mathrm{MPa}$, independent of depth, temperature, and dyke size.

The effect of viscoelasticity is negligible if the temperature of the surrounding host rock initially is low (around $0{ }^{\circ} \mathrm{C}$ ). This is true even for relatively large dykes with thicknesses in the range of tens of metres or more which have the greatest capacity to heat the surrounding rock, and which also exhibit the longest solidification time during which viscous flow could operate. However, the picture changes dramatically when the background temperature is elevated, either due to depth in a typical geotherm, or due to an elevated geotherm caused by thinned lithosphere and by local heating due to preceding volcanic intrusions. Higher host-rock temperature causes a broad-scale reduction in the viscosity, it increases the solidification time, and once there is an additional inflow of hot magma due to dyke widening, a positive feedback is activated because the inflow of heat results in a further increase in the solidification time. These effects are functions of the host-rock lithology (which dictates the viscosity as a function of temperature) and of overall dyke size (because the solidification time scales with the diffusion time, which in turn is dependent on the length scale of the system). For dykes around a metre in thickness intruding into a quartzite host rock, we find that viscous flow becomes significant around temperatures of $200{ }^{\circ} \mathrm{C}$, and the positive feedback results in a thermal runaway effect at about $280{ }^{\circ} \mathrm{C}$. 
Observations of dyke aspect ratios in conjunction with the analytical solution for pressurized cracks in a linear elastic medium are often used to estimate magma overpressures (Sneddon \& Lowengrub 1969; Gudmundsson 2011). We show in this study that the simple elastic solution generally yields an overestimate of the magma pressure. Under near-surface conditions where brecciation and frictional slip are adequately modelled by von Mises plasticity, the actual overpressures may be lower by as much as an order of magnitude relative to the elastic solution. At depth, the discrepancies may be similar due to viscous flow in a hot environment or if volatiles are present at high pore pressure. A better understanding of rock deformation under appropriate in-situ conditions is needed, including high temperatures and high strains, confining pressures up to a few hundred $\mathrm{MPa}$, and the effect of volatiles over length scales of metres or perhaps tens of metres or more.

We suggest two additional mechanisms that were not tested in this study, but which may alter dyke geometry and thickness. One is the effect of the free surface. At a depth of $1 \mathrm{~km}$, the overburden pressure is around $25 \mathrm{MPa}$. Magma overpressure of the same order of magnitude may cause significant surface uplift, and for nearly horizontal dykes (sills) may cause a transition towards a laccolith. The second mechanism is the potential interplay between dyke inflation and dyke propagation. In the present study, the question of dyke propagation was omitted altogether. However, stress concentrations at the dyke tip generally lead to dyke propagation, whereas blunting of the dyke tips, for example by plastic deformation, causes a reduction in the stress concentration and may thus arrest propagation. Better constraints on the processes involved in dyke propagation are needed.

\section{ACKNOWLEDGEMENTS}

We would like to thank K. Daniels and J. Kavanagh for providing their dyke thickness data from Rum island. We also acknowledge an anonymous reviewer for comments which greatly helped improve and clarify the manuscript.

\section{REFERENCES}

Annen, C., Lénat, J.-F. \& Provost, A., 2001. The long-term growth of volcanic edifices: numerical modelling of the role of dyke intrusion and lava-flow emplacement, J. Volcanol. Geotherm. Res., 105(4), 263-289.

Asef, M.R. \& Najibi, A.R., 2013. The effect of confining pressure on elastic wave velocities and dynamic to static Young's modulus ratio, Geophysics, 78(3), D135-D142.

Atkinson, B.K., 1984. Subcritical crack growth in geological materials, J. geophys. Res., 89(B6), 4077-4114.

Becerril, L., Galindo, I., Gudmundsson, A. \& Morales, J.M., 2013. Depth of origin of magma in eruptions, Sci. Rep., 3, doi:10.1038/srep02762.

Bruce, P.M. \& Huppert, H.E., 1990. Solidification and melting along dykes by the laminar flow of basaltic magma, in Magma Transport and Storage, pp. 87-101, ed. Ryan, M.P., Wiley.

Clauser, C. \& Huenges, E., 1995. Thermal conductivity of rocks and minerals, in Rock Physics \& Phase Relations: A Handbook of Physical Constants, pp. 105-126, ed. Ahrens, T.J., American Geophysical Union.

Clifton, R.J., Simonson, E.R., Jones, A.H. \& Green, S.J., 1976. Determination of the critical-stress-intensity factor KIc from internally pressurized thick-walled vessels, Exp. Mech., 16(6), 233-238.

Costa, A., Melnik, O. \& Sparks, R., 2007. Controls of conduit geometry and wallrock elasticity on lava dome eruptions, Earth planet. Sci. Lett., 260(1), 137-151.

Daniels, K.A., Kavanagh, J.L., Menand, T. \& Stephen, J.S.R., 2012. The shapes of dikes: evidence for the influence of cooling and inelastic deformation, Bull. geol. Soc. Am., 124(7-8), 1102-1112.
David, E. \& Zimmerman, R.W., 2012. Pore structure model for elastic wave velocities in fluid-saturated sandstones, J. geophys. Res., 117(B7), doi:10.1029/2012JB009195.

Delaney, P.T. \& Pollard, D.D., 1981. Deformation of host rocks and flow of magma during growth of minette dikes and breccia-bearing intrusions near Ship Rock, New Mexico, USGS Numbered Series 1202, U.S. G.P.O.

Emeleus, C.H. \& Hudson, J.D., 1997. Geology of Rum and the Adjacent Islands: Memoir for 1:50 000 Geological Sheet 60 (Scotland), vol. 60, H.M.S.0.

Geshi, N., Kusumoto, S. \& Gudmundsson, A., 2010. Geometric difference between non-feeder and feeder dikes, Geology, 38(3), 195-198.

Groenenboom, J. \& van Dam, D.B., 2000. Monitoring hydraulic fracture growth: laboratory experiments, Geophysics, 65(2), 603-611.

Gudmundsson, A., 1995. The geometry and growth of dykes, in Physics and Chemistry of Dykes, pp. 23-34, eds Baer, G. \& Heimann, A., A.A. Balkema Publisher.

Gudmundsson, A., 2009. Toughness and failure of volcanic edifices, Tectonophysics, 471(1-2), 27-35.

Gudmundsson, A., 2011. Rock Fractures in Geological Processes, Cambridge Univ. Press.

Hamilton, M., Pearson, D., Thompson, R., Kelley, S. \& Emeleus, C., 1998. Rapid eruption of Skye lavas inferred from precise $\mathrm{U}-\mathrm{Pb}$ and $\mathrm{Ar}-\mathrm{Ar}$ dating of the Rum and Cuillin plutonic complexes, Nature, 394(6690), 260-263.

Henyey, F.S. \& Pomphrey, N., 1982. Self-consistent elastic moduli of a cracked solid, Geophys. Res. Lett., 9(8), 903-906.

Hertzberg, R.W., 2012. Deformation and Fracture Mechanics of Engineering Materials, 5th edn, John Wiley and Sons.

Hill, R., 1998. The Mathematical Theory of Plasticity, vol. 11, Oxford Univ. Press.

Hoek, J., 1995. Dyke propagation and arrest in Proterozoic tholeiitic dyke swarms, Vestfold Hills, East Antarctica, in Physics and Chemistry of Dykes, pp. 79-93, eds Baer, G. \& Heimann, A., A.A. Balkema Publisher.

Jaeger, J.C., Cook, N.G. \& Zimmerman, R., 2009. Fundamentals of Rock Mechanics, John Wiley \& Sons.

Jellinek, A.M. \& DePaolo, D.J., 2003. A model for the origin of large silicic magma chambers: precursors of caldera-forming eruptions, Bull. Volcanol., 65(5), 363-381.

Karlstrom, L., Dufek, J. \& Manga, M., 2009. Organization of volcanic plumbing through magmatic lensing by magma chambers and volcanic loads, J. geophys. Res., 114(B10), doi:10.1029/2009JB006339.

Kavanagh, J. \& Sparks, R.S.J., 2011. Insights of dyke emplacement mechanics from detailed 3D dyke thickness datasets, J. Geol. Soc., 168(4), 965-978.

Kavanagh, J., Menand, T. \& Daniels, K.A., 2013. Gelatine as a crustal analogue: determining elastic properties for modelling magmatic intrusions, Tectonophysics, 582, 101-111.

Khazanehdari, J. \& Sothcott, J., 2003. Variation in dynamic elastic shear modulus of sandstone upon fluid saturation and substitution, Geophysics, 68(2), 472-481.

Krumbholz, M., Hieronymus, C.F., Burchardt, S., Troll, V.R., Tanner, D.C. \& Friese, N., 2014. Weibull-distributed dyke thickness reflects probabilistic character of host-rock strength, Nat. Commun., 5, doi: $10.1038 /$ ncomms 4272 .

Kusumoto, S. \& Gudmundsson, A., 2014. Displacement and stress fields around rock fractures opened by irregular overpressure variations, Front. Earth Sci., 2, doi:10.3389/feart.2014.00007.

Kusumoto, S., Geshi, N. \& Gudmundsson, A., 2013. Aspect ratios and magma overpressures of non-feeder dikes observed in the Miyake-jima volcano (Japan), and fracture toughness of its upper part, Geophys. Res. Lett., 40(6), 1065-1068.

Lawn, B., 1993. Fracture of Brittle Solids, Cambridge Univ. Press.

Lister, J.R., 1990. Buoyancy-driven fluid fracture: the effects of material toughness and of low-viscosity precursors, J. Fluid Mech., 210, 263-280.

Maaløe, S., 1998. Shape of ascending feeder dikes, and ascent modes of magma, J. Volcanol. Geotherm. Res., 81(3), 207-214. 
Newman, A., Dixon, T.H., Ofoegbu, G. \& Dixon, J., 2001. Geodetic and seismic constraints on recent activity at Long Valley Caldera, California: evidence for viscoelastic rheology, J. Volcanol. Geotherm. Res., 105(3), 183-206.

Nicoll, G.R., Holness, M.B., Troll, V.R., Donaldson, C.H., Holohan, E.P., Emeleus, C.H. \& Chew, D., 2009. Early mafic magmatism and crustal anatexis on the Isle of Rum: evidence from the Am Mam intrusion breccia, Geol. Mag., 146(3), 368-381.

Parfitt, E.A., 1991. The role of rift zone storage in controlling the site and timing of eruptions and intrusions of Kilauea Volcano, Hawaii, J. geophys. Res., 96(B6), 10 101-10 112.

Paterson, M.S. \& Wong, T.-f., 2005. Experimental Rock Deformation: The Brittle Field, Springer Science \& Business Media.

Poland, M.P., Moats, W.P. \& Fink, J.H., 2008. A model for radial dike emplacement in composite cones based on observations from Summer Coon volcano, Colorado, USA, Bull. Volcanol,, 70(7), 861-875.

Pollard, D.D. \& Muller, O.H., 1976. The effect of gradients in regional stress and magma pressure on the form of sheet intrusions in cross section, $J$. geophys. Res., 81(5), 975-984.

Qin, R. \& Buck, W.R., 2008. Why meter-wide dikes at oceanic spreading centers?, Earth planet. Sci. Lett., 265(3), 466-474.

Ranalli, G., 1995. Rheology of the Earth, Springer Science \& Business Media.

Rasmussen, J., 1978. Schematic 3-d model of a dyke in the Faeroese basalt plateau, Bull. Geol. Soc., 27, 79-84.

Reiners, P.W., Nelson, B.K. \& Ghiorso, M.S., 1995. Assimilation of felsic crust by basaltic magma: thermal limits and extents of crustal contamination of mantle-derived magmas, Geology, 23(6), 563-566.
Rivalta, E. \& Dahm, T., 2006. Acceleration of buoyancy-driven fractures and magmatic dikes beneath the free surface, Geophys. J. Int., 166(3), 1424-1439.

Rubin, A.M., 1993. Tensile fracture of rock at high confining pressure: implications for dike propagation, J. geophys. Res., 98(B9), 15 91915935.

Rubin, A.M. \& Pollard, D.D., 1987. Origins of blade-like dikes in volcanic rift zones, United States Geological Survey Professional Paper 1350.

Rudnicki, J.W. \& Rice, J., 1975. Conditions for the localization of deformation in pressure-sensitive dilatant materials, J. Mech. Phys. Solids, 23(6), 371-394.

Saxena, A. \& Landes, J.D., 1989. Nonlinear Fracture Mechanics: ElasticPlastic Fracture, ASTM International.

Sneddon, I.N. \& Lowengrub, M., 1969. Crack Problems in the Classical Theory of Elasticity, Wiley.

Spence, D. \& Turcotte, D., 1985. Magma-driven propagation of cracks, J. geophys. Res., 90(B1), 575-580.

Tada, H., Paris, P. \& Irwin, G., 2000. The Stress Analysis of Cracks Handbook (3rd ed.) International Edition, McGraw-Hill.

Timoshenko, S. \& Goodier, J., 1970. Theory of Elasticity, 3rd edn, McGrawHill.

Turcotte, D.L. \& Schubert, G., 2002. Geodynamics, 2nd edn, Cambridge Univ. Press.

Vermeer, P.A. \& De Borst, R., 1984. Non-Associated Plasticity for Soils, Concrete and Rock, Delft University of Technology.

Walsh, J., 1965. The effect of cracks on the compressibility of rock, J. geophys. Res., 70(2), 381-389. 